\title{
Psychological therapies (Internet-delivered) for the management of chronic pain in adults (Review)
}

Eccleston C, Fisher E, Brown R, Craig L, Duggan GB, Rosser BA, Keogh E

Eccleston C, Fisher E, Brown R, Craig L, Duggan GB, Rosser BA, Keogh E.

Psychological therapies (Internet-delivered) for the management of chronic pain in adults.

Cochrane Database of Systematic Reviews 2014, Issue 2. Art. No.: CD010152.

DOI: 10.1002/14651858.CD010152.pub2.

www.cochranelibrary.com 
TABLE OF CONTENTS

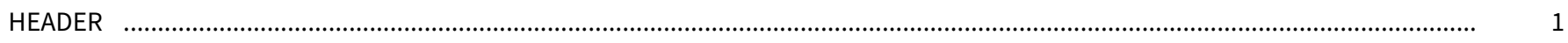

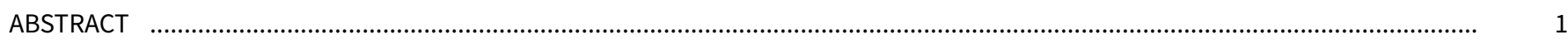

PLAIN LANGUAGE SUMMARY

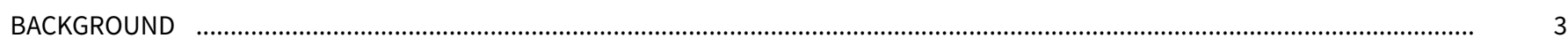

OBJECTIVES

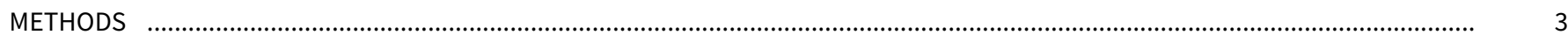

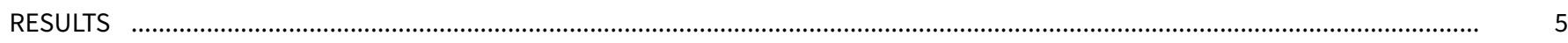

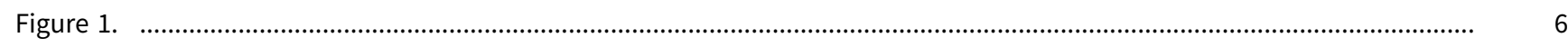

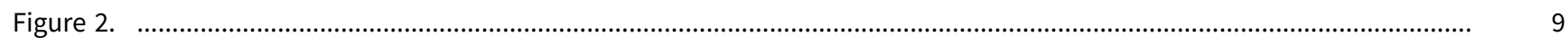

Figure 3.

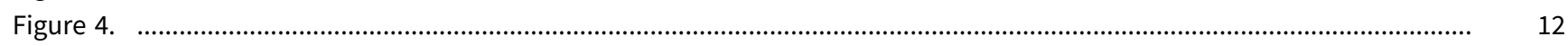

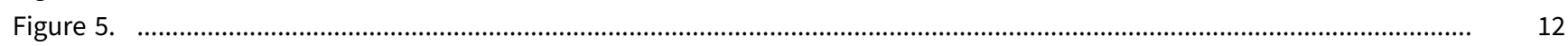

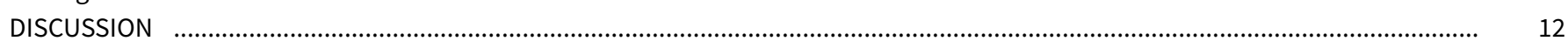

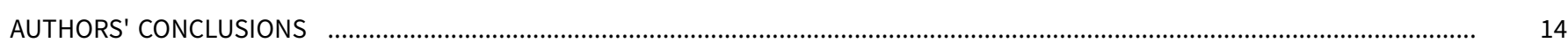

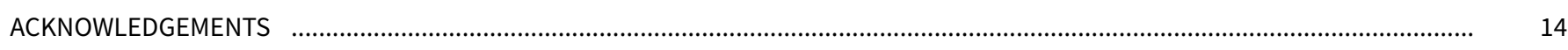

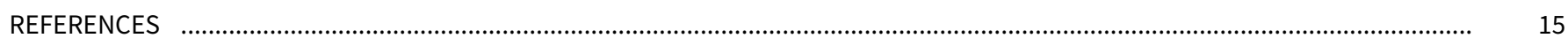

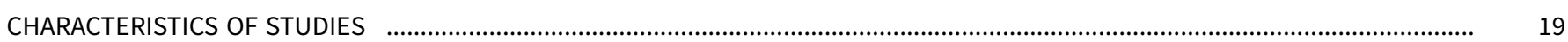

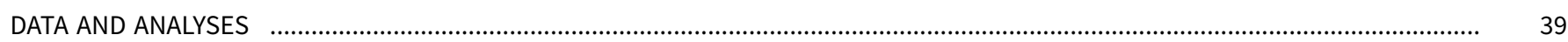

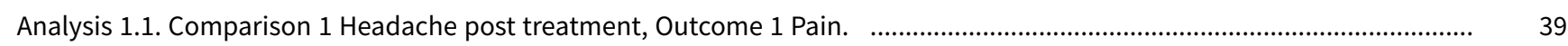

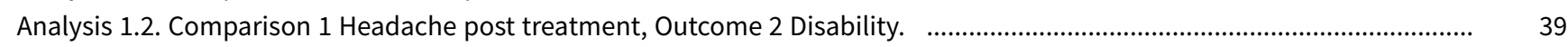

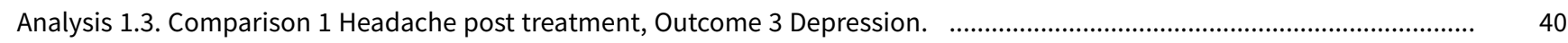

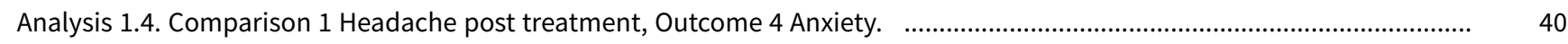

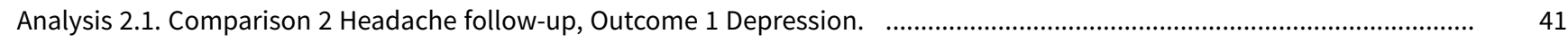

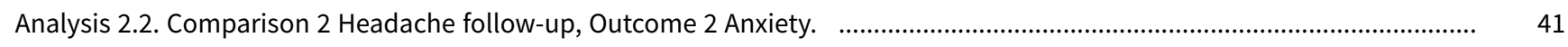

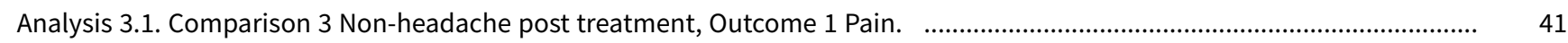

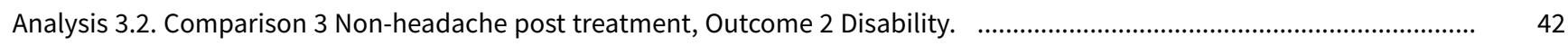

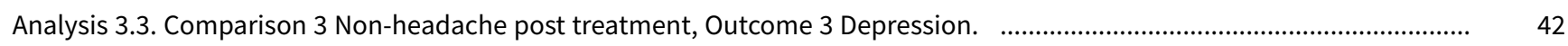

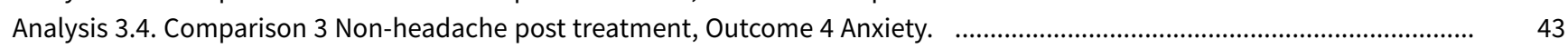

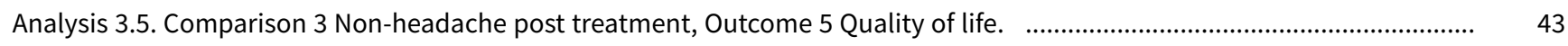

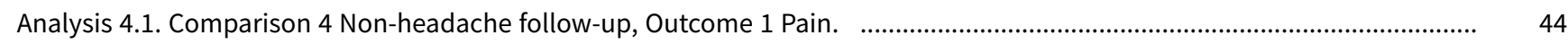

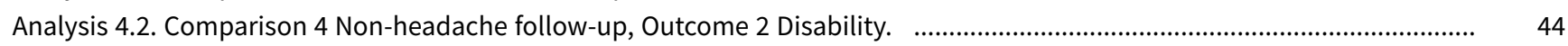

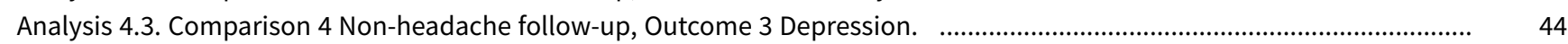

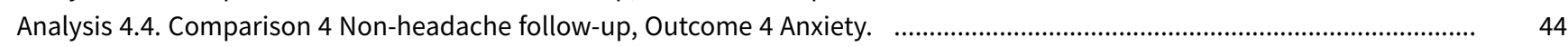

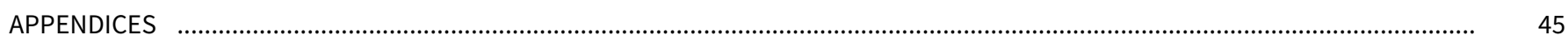

WHAT'S NEW

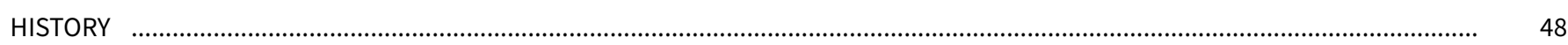

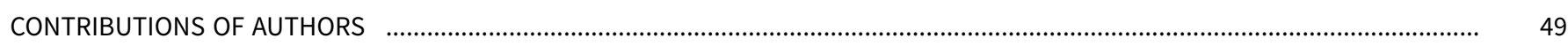

DECLARATIONS OF INTEREST

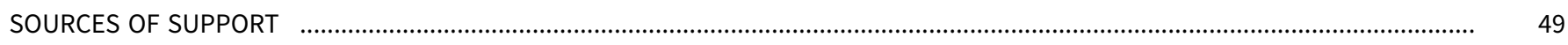

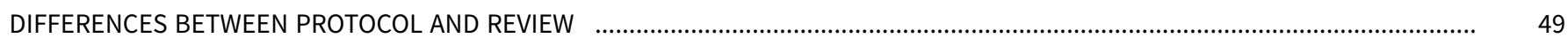

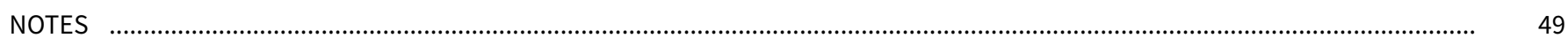

INDEX TERMS 
[Intervention Review]

\section{Psychological therapies (Internet-delivered) for the management of chronic pain in adults}

Christopher Eccleston¹, Emma Fisher2, Randi Brown³, Lorraine Craig4, Geoffrey B Duggan¹, Benjamin A Rosser5, Edmund Keogh6

${ }^{1}$ Centre for Pain Research, University of Bath, Bath, UK. ${ }^{2}$ Cochrane Pain, Palliative and Supportive Care Group, Pain Research Unit, Churchill Hospital, Oxford, UK. ${ }^{3}$ Clinical Psychology, Palo Alto University, Palo Alto, USA. ${ }^{2}$ Department of Health, University of Bath, Bath, UK. ${ }^{5}$ University of Exeter, Exeter, UK. ${ }^{6}$ Department of Psychology, University of Bath, Bath, UK

Contact address: Christopher Eccleston, Centre for Pain Research, University of Bath, Claverton Down, Bath, UK. papas@bath.ac.uk, c.eccleston@bath.ac.uk.

Editorial group: Cochrane Pain, Palliative and Supportive Care Group

Publication status and date: Stable (no update expected for reasons given in 'What's new'), published in Issue 9, 2019.

Citation: Eccleston C, Fisher E, Brown R, Craig L, Duggan GB, Rosser BA, Keogh E. Psychological therapies (Internet-delivered) for the management of chronic pain in adults. Cochrane Database of Systematic Reviews 2014, Issue 2. Art. No.: CD010152. DOI: 10.1002/14651858.CD010152.pub2.

Copyright $@ 2019$ The Cochrane Collaboration. Published by John Wiley \& Sons, Ltd.

\section{A B S T R A C T}

\section{Background}

Chronic pain (i.e. pain lasting longer than three months) is common. Psychological therapies (e.g. cognitive behavioural therapy) can help people to cope with pain, depression and disability that can occur with such pain. Treatments currently are delivered via hospital outpatient consultation (face-to-face) or more recently through the Internet. This review looks at the evidence for psychological therapies delivered via the Internet for adults with chronic pain.

\section{Objectives}

Our objective was to evaluate whether Internet-delivered psychological therapies improve pain symptoms, reduce disability, and improve depression and anxiety for adults with chronic pain. Secondary outcomes included satisfaction with treatment/treatment acceptability and quality of life.

\section{Search methods}

We searched CENTRAL (Cochrane Library), MEDLINE, EMBASE and PsycINFO from inception to November 2013 for randomised controlled trials (RCTs) investigating psychological therapies delivered via the Internet to adults with a chronic pain condition. Potential RCTs were also identified from reference lists of included studies and relevant review articles. In addition, RCTs were also searched for in trial registries.

\section{Selection criteria}

Peer-reviewed RCTs were identified and read in full for inclusion. We included studies if they used the Internet to deliver the primary therapy, contained sufficient psychotherapeutic content, and promoted self-management of chronic pain. Studies were excluded if the number of participants in any arm of the trial was less than 20 at the point of extraction.

\section{Data collection and analysis}

Fifteen studies met the inclusion criteria and data were extracted. Risk of bias assessments were conducted for all included studies. We categorised studies by condition (headache or non-headache conditions). Four primary outcomes; pain symptoms, disability, depression, and anxiety, and two secondary outcomes; satisfaction/acceptability and quality of life were extracted for each study immediately posttreatment and at follow-up (defined as 3 to 12 months post-treatment). 


\section{Main results}

Fifteen studies ( $\mathrm{N}=2012)$ were included in analyses. We assessed the risk of bias for included studies as low overall. We identified nine high 'risk of bias' assessments, 22 unclear, and 59 low 'risk of bias' assessments. Most judgements of a high risk of bias were due to inadequate reporting.

Analyses revealed seven effects. Participants with headache conditions receiving psychological therapies delivered via the Internet had reduced pain (number needed to treat to benefit $=2.72$, risk ratio $7.28,95 \%$ confidence interval $(\mathrm{Cl}) 2.67$ to $19.84, p<0.01$ ) and a moderate effect was found for disability post-treatment (standardised mean difference (SMD) $-0.65,95 \% \mathrm{Cl}-0.91$ to $-0.39, p<0.01$ ). However, only two studies could be entered into each analysis; hence, findings should be interpreted with caution. There was no clear evidence that psychological therapies improved depression or anxiety post-treatment (SMD $-0.26,95 \% \mathrm{Cl}-0.87$ to $0.36, p>0.05 ; \mathrm{SMD}-0.48,95 \% \mathrm{Cl}-1.22$ to $0.27, p>0.05)$, respectively. In participants with non-headache conditions, psychological therapies improved pain post-treatment $(p<$ 0.01 ) with a small effect size (SMD $-0.37,95 \% \mathrm{Cl}-0.59$ to -0.15$)$, disability post-treatment $(p<0.01)$ with a moderate effect size (SMD -0.50 , $95 \% \mathrm{Cl}-0.79$ to -0.20$)$, and disability at follow-up $(p<0.05)$ with a small effect size (SMD $-0.15,95 \% \mathrm{Cl}-0.28$ to -0.01$)$. However, the followup analysis included only two studies and should be interpreted with caution. A small effect was found for depression and anxiety posttreatment (SMD $-0.19,95 \% \mathrm{Cl}-0.35$ to $-0.04, p<0.05$; SMD $-0.28,95 \% \mathrm{Cl}-0.49$ to $-0.06, p<0.01$ ), respectively. No clear evidence of benefit was found for other follow-up analyses. Analyses of adverse effects were not possible.

No data were presented on satisfaction/acceptability. Only one study could be included in an analysis of the effect of psychological therapies on quality of life in participants with headache conditions; hence, no analysis could be undertaken. Three studies presented quality of life data for participants with non-headache conditions; however, no clear evidence of benefit was found (SMD $-0.27,95 \% \mathrm{Cl}$ -0.54 to $0.01, p>0.05$ ).

\section{Authors' conclusions}

There is insufficient evidence to make conclusions regarding the efficacy of psychological therapies delivered via the Internet in participants with headache conditions. Psychological therapies reduced pain and disability post-treatment; however, no clear evidence of benefit was found for depression and anxiety. For participants with non-headache conditions, psychological therapies delivered via the Internet reduced pain, disability, depression, and anxiety post-treatment. The positive effects on disability were maintained at follow-up. These effects are promising, but considerable uncertainty remains around the estimates of effect. These results come from a small number of trials, with mostly wait-list controls, no reports of adverse events, and non-clinical recruitment methods. Due to the novel method of delivery, the satisfaction and acceptability of these therapies should be explored in this population. These results are similar to those of reviews of traditional face-to-face therapies for chronic pain.

\section{PLAIN LANGUAGE SUMMARY}

\section{Psychological therapies delivered via the Internet for adults with longstanding distressing pain and disability}

Chronic pain (i.e. pain lasting longer than three months) is common. Psychological therapies (e.g. cognitive behavioural therapy) can help people to cope with pain, depression and disability that can occur with such pain. Treatments currently are delivered via hospital outpatient consultation (face-to-face) or more recently through the Internet. This review looks at the evidence for psychological therapies delivered via the Internet for adults with chronic pain.

Four databases were searched up to November 2013. We found 15 trials that met our inclusion criteria. Four trials included individuals with headache pain, 10 trials included individuals with non-headache pain, and one trial included individuals with both headache and nonheadache pain. We looked at data about pain, disability, depression, and anxiety immediately after the end of treatment and between 3 to 12 months follow-up. We also looked at how satisfied people were with the treatments, and its effects on their quality of life.

We found that for people with headache pain, pain symptoms and disability scores improved immediately following the end of treatment. However, only two trials could be entered into each of these analyses and so findings should be treated with caution. For people with nonheadache pain, pain, disability, depression, and anxiety improved immediately after the end of treatment. Disability was also improved at follow-up. Only one study recorded quality of life scores in individuals with headache pain, so we were unable to analyse the results. Three studies presented quality of life scores for individuals with non-headache pain immediately following treatment. We did not find that quality of life improved after receiving the therapy. No data could be analysed on treatment satisfaction/acceptability.

We conclude that these findings are promising for psychological treatments delivered via the Internet for the management of chronic pain in adults, but more trials are needed to determine the efficacy of such therapies. 


\section{B A C K G R O U N D}

\section{Description of the condition}

Chronic pain is prevalent in both adult and child populations (Breivik 2006; King 2011; Standford 2008), impacting on physical, psychological, and social functioning. Given that chronic pain is a long-term health condition, sustainable solutions to problems of pain, disability, depression, and anxiety are needed. Individuals experiencing chronic pain should be able to access selfmanagement therapies away from expert healthcare centres, and be enabled to sustain self-management over the long-term. There is an opportunity for Internet-delivered therapies to provide methods that support this self-management.

\section{Description of the intervention}

Inconsistent terminology, including telemedicine, telehealth, ehealth, and Internet-delivered therapy, are commonly used interchangeably. Here, we use the term 'Internet-delivered therapies' to encompass technology that uses the worldwide web and facilitates the multifaceted, often psychotherapeutic, approach to modern chronic pain management (Gatchel 2007; Williams 2012). Internet-delivered therapies are only one part of a larger telehealth family of interventions that can assist communication between practitioner and patient, and improve self-management. The potential benefits of telehealth interventions include increased access to healthcare resources, not limited by geographic location or personnel availability, and reduced costs (Jennett 2003). Although remote consultation between the healthcare professional (HCP) and patient may contribute to these benefits, this review is limited to the use of Internet-delivered psychological therapies that use technology as a medium for facilitating traditional therapy delivery. For example, an Internet-based pain management intervention (e.g. Berman 2009) would meet this criterion, whereas an intervention providing traditional therapy by telephone (e.g. Sandgren 2000) would not. Previous research suggests that Internet-delivered treatment in the absence of, or with minimal, HCP involvement may be an effective intervention for chronic pain (Bender 2011; Palermo 2009). Such interventions frequently focus on the reduction of pain intensity and emotional distress, and the encouragement of adaptive behaviour change and skills acquisition. This focus is congruent with policy directives in many countries that advocate self-management and patient empowerment in the treatment of long-term health conditions, such as chronic pain (Bodenheimer 2002; Fu 2003; Jordan 2007; Lewis 2004). The evaluation of the efficacy of standalone Internetdelivered therapy is integral to substantiating whether these types of interventions can facilitate the successful evolution of health care away from the traditional and unsustainable acute model of care. In short, this review assesses whether pain management therapies can be successfully delivered in the home using the Internet as a mode of delivery.

\section{How the intervention might work}

The use of Internet-delivered therapies for pain-related health care takes a variety of forms, from assessment and education to structured intervention programmes (Keogh 2010). The mechanisms through which Internet-delivered therapies operate vary depending on technology, content, and health condition. The standalone (or minimally facilitated) therapies included in this review are likely to be based on adaptations of established methods of psychological pain management. However, one cannot assume that the impact and function of treatment will be equivalent. The introduction of technology and the reduction, or absence, of human interaction in treatment delivery has the potential to significantly influence the experience of the intervention and, ultimately, the outcome. A function of this review will be to establish, where possible, relations between features of technology, therapy content, and treatment outcome.

\section{Why it is important to do this review}

This review is designed to complement the review on psychological interventions for chronic pain in adults that excluded psychological or behaviour change therapies delivered over the Internet (Williams 2012). Relevant reviews of similar Internet-based therapies in nonpain conditions include those that focus on a specific targeted behaviour such as smoking cessation (Civljak 2013), or sexual health promotion (Bailey 2010), or those with a focus on a range of relevant behaviours within a lifestyle, such as selfmanagement of type 2 diabetes mellitus (Pal 2013). These reviews have found some evidence for treatment effectiveness but are inconsistent on the economic benefits of telehealth (Black 2011), and there is a lack of analysable data when comparing telehealth interventions with traditional treatment approaches (Bailey 2010; Currell 2000). Furthermore, the quality of telehealth interventions and existing reviews (Martin 2008; Tuntland 2009; Whitten 2007) has been questioned (Black 2011). Evidence supporting the utility of Internet-delivered therapies for chronic pain appears more consistent. For example, Internet-delivered cognitive behavioural therapy (CBT) for chronic pain has produced clinically significant improvements in pain intensity in both adult and child populations (Bender 2011; Palermo 2009; Velleman 2010). At present, there is no systematic evaluation of the broader potential applications of psychological therapies delivered via the Internet. Furthermore, the moderating impact of demographic characteristics, including age, technology employed, and health condition, on treatment outcome within Internet-delivered therapies has yet to be explored within chronic pain (Hardiker 2011; McLean 2010; McLean 2011) .

\section{O B JECT IVES}

Our objective was to evaluate whether Internet-delivered psychological therapies improve pain symptoms, reduce disability, and improve depression and anxiety in adults with chronic pain. Secondary outcomes included satisfaction with treatment/ treatment acceptability and quality of life.

\section{METHODS}

\section{Criteria for considering studies for this review}

\section{Types of studies}

We included randomised controlled trial (RCT) comparisons of Internet-delivered therapy for chronic pain compared to an active control, treatment-as-usual, or waiting-list control in this review. Studies had to include 20 or more participants with each condition at each extracted time-point (post-treatment and follow-up). We considered only peer-reviewed publications for inclusion in this review. We included trials if the primary aim was to deliver and evaluate a self-management psychological therapy in adults with chronic non-cancer pain. 


\section{Types of participants}

Adults (aged 18 years or older) who reported non-cancer chronic pain. Studies included participants with headache or migraine (headache conditions) and pain in any body site (e.g. back pain, abdominal pain, musculoskeletal pain, fibromyalgia) (nonheadache conditions). Chronic pain was defined as the experience of pain for three months or longer. Mixed-aged samples were included when adult and child data could be separated. We included studies in this review if the sample of participants was predominantly made up of those with chronic pain conditions.

\section{Types of interventions}

Included studies used an Internet-delivered psychological therapy that was required to be interactive with the user (e.g. respond dynamically based on data input by the user). Technology capable of delivering a psychological treatment programme via the Internet in the absence of, or with limited adjunctive HCP involvement was included. Adjunctive HCP involvement was categorised as involvement that supported a technology-based therapy, but that was not the primary source of treatment. The treatment therapy needed to be designed to promote pain management, by reducing pain experience, disability, and psychological distress, or adaptive behaviour change, or both. Therapies had to be based on an extant psychological model or framework, therefore including credible psychological content. Included studies needed to contain at least one arm using a psychological therapy and at least one comparator arm. Studies categorised as broader telehealth therapies, where technology was used to facilitate traditional communication and treatment between HCP and the individual with chronic pain, but did not deliver the primary psychological therapy itself and did not use the Internet to deliver the therapy (e.g. non-automated email, video conferencing) were excluded. However, these components were permitted to be additional parts to a Internet-delivered psychological therapy.

\section{Types of outcome measures}

\section{Primary outcomes}

The primary outcomes were pain, physical disability, depression, and anxiety. For pain outcomes, we extracted data on pain severity where possible. For studies that did not report a pain severity score, we extracted the most relevant outcome (e.g. average pain score). Pain specific measures were preferentially extracted to general measures (e.g. pain-related anxiety rather than a general anxiety measure). Adverse event data were also searched for.

\section{Secondary outcomes}

Secondary outcomes were quality of life, and treatment acceptability/satisfaction.

\section{Search methods for identification of studies}

\section{Electronic searches}

The following databases for RCTs of Internet-delivered interventions for adults with chronic pain were searched (see Appendix 1 for search strategies):

- Cochrane Central Register of Controlled Trials (CENTRAL) on The Cochrane Library, Issue 10 of 12 (2013);

- MEDLINE (OVID), 1950 to 8/11/13;

- EMBASE (OVID) 1980 to 2013 week 45 ;
- PsycINFO (OVID) 1806 to Nov week 1, 2013.

\section{Searching other resources}

We also conducted a search of the reference lists of included papers and relevant review articles to source any studies that did not appear in the electronic searches. We also searched trial registries for trials.

\section{Data collection and analysis}

\section{Selection of studies}

Only peer-reviewed studies were eligible for inclusion. Review authors (EF, LC, GBD) reviewed the titles and abstracts of studies identified by the searches to assess eligibility based on the outlined criteria. Full text of studies initially meeting the criteria, or not categorically failing to meet the criteria for final selection, were assessed. Discrepancies between review authors were resolved by discussion; in the event that resolution could not be reached, a third review author (CE) arbitrated. We selected studies for inclusion using the following criteria:

1. must be an RCT published in a peer-reviewed journal;

2. $n=>20$ in each arm at extracted time point;

3. therapy must be primarily psychological in at least one arm of the trial;

4. study must have the primary aim of promoting self-management in adults with non-cancer chronic pain;

5. study must use an Internet-delivered therapy as the primary mode of delivery.

\section{Data extraction and management}

Two review authors (EF, LC) independently extracted data from all included studies. Discrepancies between review authors were resolved by discussion; in the event that resolution could not be reached, a third review author (CE) arbitrated. Quantitative data were entered into Review Manager 5.2 (RevMan 2011). For outcome variables measured on continuous scales the standardised mean differences (SMDs) were calculated from extracted means and standard deviations (SD) collected post-intervention and at followup. For dichotomous outcomes, we calculated relative risk ratios (RR) with 95\% confidence intervals $(\mathrm{Cl})$ using a random-effects model. The number needed to treat to benefit (NNTB) was also calculated:

NNTB $=1$ /absolute risk reduction (ARR), where $A R R=$ the experimental event rate - the control event rate.

Where the necessary data were not reported, study authors were contacted. In addition to outcome data, participant demographic data were extracted and reported from the included studies.

\section{Assessment of risk of bias in included studies}

Two review authors assessed risk of bias using the Cochrane method (Higgins 2011), focusing on the evaluation of sequence generation, allocation concealment, blinding (outcome assessors), incomplete data, selective outcome reporting, and assessing other biases. Blinding of participants and personnel was not included in this review, as this category is redundant when reviewing psychological treatments (i.e. it is not possible to blind personnel to delivery of therapy). We categorised the risk of bias for each study as 'low', 'unclear', or 'high'. Discrepancies between authors were 
resolved by discussion; in the event that resolution could not be reached, a third review author arbitrated.

\section{Measures of treatment effect}

Chronic pain conditions were split into headache and nonheadache conditions. Control groups were combined for this review due to the small number of included studies. Each of the four primary outcomes and the two secondary outcomes were extracted and analysed post-treatment and at follow-up. If more than two measures were presented for one outcome, we extracted the most reliable and frequently used measure in the field. Self-report data were preferentially extracted. Post-treatment refers to the timepoint first measured after treatment completion. The accepted timeframe for the collection of follow-up data was 3 to 12 months post-intervention. Data outside of this time frame were excluded. In the event of multiple follow-ups within the timeframe we used the latest data collection point. When a trial included more than two arms, we combined the results from the two most similar arms. If it was not appropriate to combine two arms together, (e.g. testing two different psychological therapies versus a control) the control group was split (Higgins 2011). Meta-analyses are presented only when two or more studies could be included for a given outcome.
We conducted no sensitivity analyses because of the small number of studies.

\section{Assessment of heterogeneity}

We assessed heterogeneity by calculating the $\mathrm{Chi}^{2}$ and $\mathrm{I}^{2}$ statistics for all outcome variables. We considered values for the $\mathrm{I}^{2}$ statistic above $50 \%$ to indicate high levels of heterogeneity, values between $25 \%$ and $50 \%$ to indicate medium heterogeneity, and those below $25 \%$ to indicate low heterogeneity.

\section{RES U LTS}

\section{Description of studies}

See: Characteristics of included studies and Characteristics of excluded studies.

\section{Results of the search}

The database search of CENTRAL, MEDLINE, EMBASE, and PsycINFO generated a total of 9390 papers (see Figure 1). Fifteen studies met the full inclusion criteria. 
Figure 1. Study flow diagram.

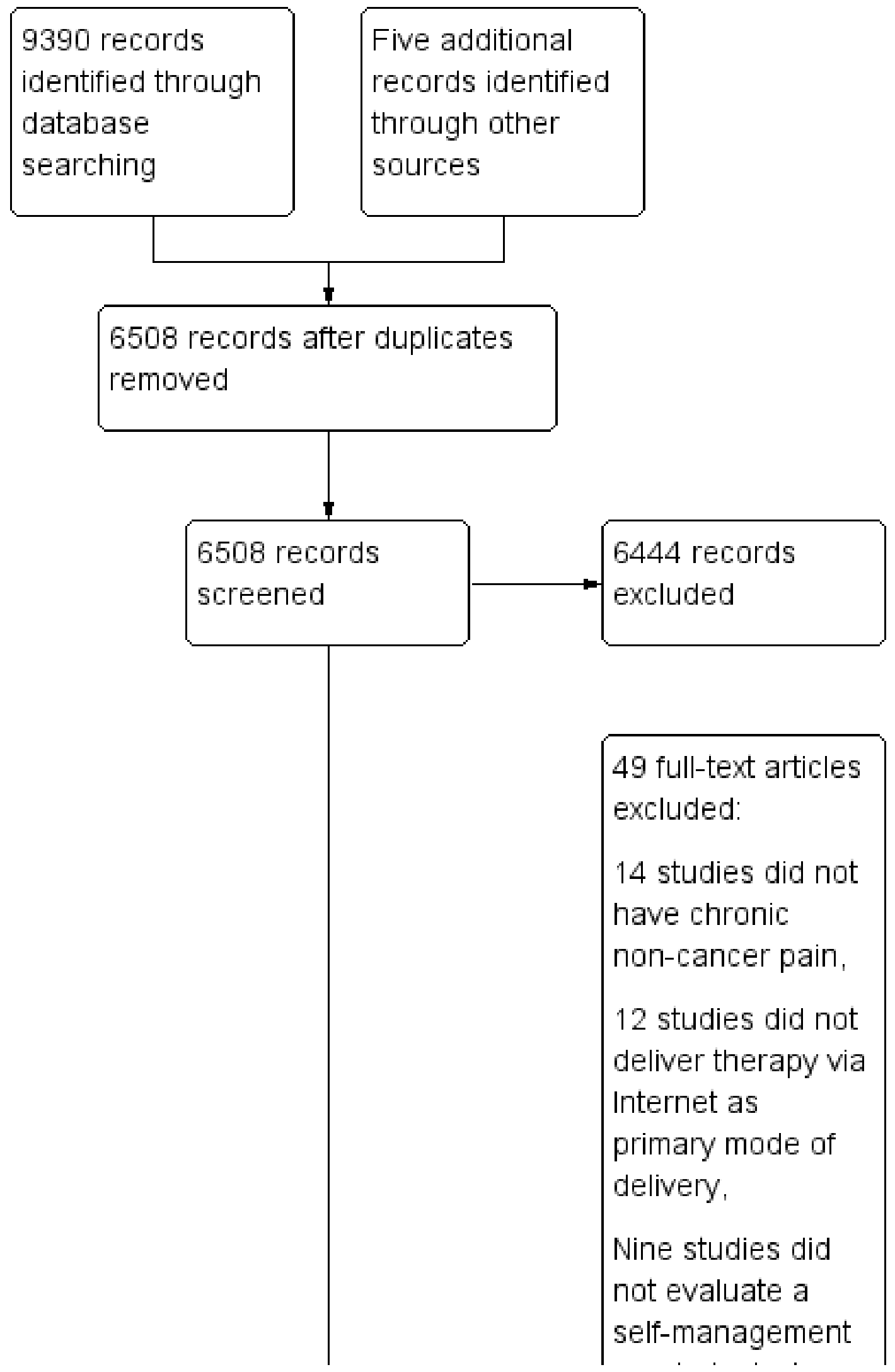


Figure 1. (Continued)

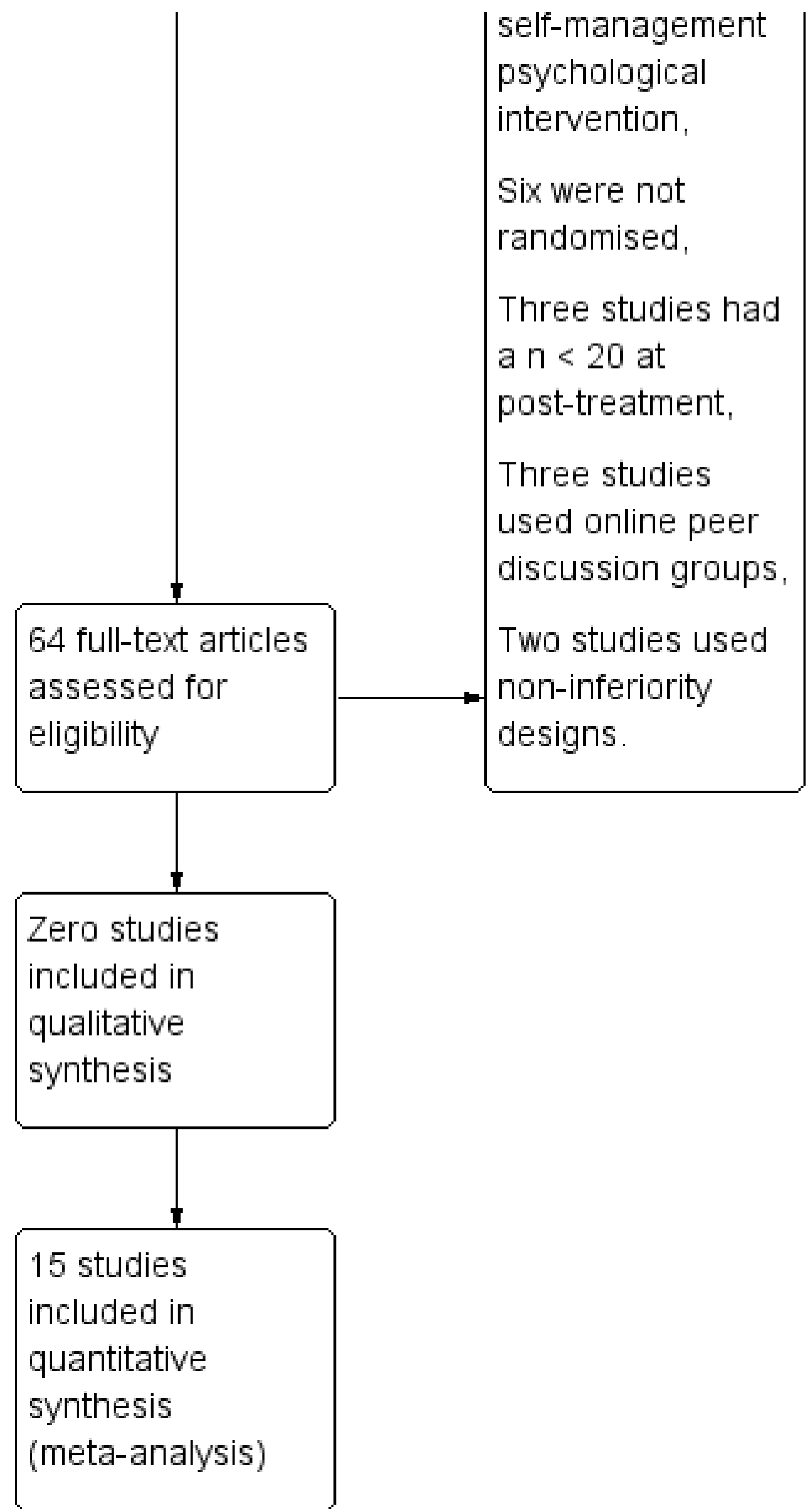




\section{Included studies}

We categorised the 15 studies on the basis of chronic pain condition: headache conditions (Bromberg 2011; Devineni 2005; Hedborg 2011; Ruehlman 2012; Strom 2000) and non-headache conditions (Berman 2009; Buhrman 2004; Buhrman 2011; Buhrman 2013; Buhrman 2013a; Carpenter 2012; Chiauzzi 2010; Dear 2013; Lorig 2008; Ruehlman 2012; Williams 2010). Ruehlman 2012 considered mixed pain conditions, including headache and back pain and is therefore included in both analyses (headache and non-headache conditions). Of the five studies included within the headache conditions category, three studies included individuals with migraines (Bromberg 2011; Hedborg 2011; Ruehlman 2012), one included individuals with chronic headache (Devineni 2005), and one included individuals with recurrent headache (Strom 2000). In the non-headache conditions category, five studies included individuals with chronic back pain (Buhrman 2004; Buhrman 2011; Carpenter 2012; Chiauzzi 2010; Ruehlman 2012), two included individuals with rheumatoid arthritis, osteoarthritis, or fibromyalgia (Lorig 2008; Williams 2010) and four included individuals with mixed pain conditions (i.e. not headache; Berman 2009; Buhrman 2013; Buhrman 2013a; Dear 2013).

The total number of participants providing data at the end of treatment was 2012 (mean $=134$ participants per study, SD = 151 , median $=78$, interquartile range (IQR) 56 to 144). The total number of participants entering treatment was 2435 (mean $=162$ participants per study, $\mathrm{SD}=204.68$, median $=86, \mathrm{IQR}=62$ to 189 ). Therefore the completion rate for all studies was $82.6 \%$, with the proportion of completers ranging across studies from $75 \%$ to $100 \%$. The attrition rate was $17.4 \%$ (range 0 to $25 \%$ ). The mean age of participants entering the studies was 47 years $(S D=7.59$ years, range $=37$ to 66 years, median $=44.93$ years, IQR $=42.50$ to 50.46 years). Mean duration of pain was reported in only eight studies ( mean $=11.69$ years, $S D=5.53$ years, range $=9$ to 23 years, median $=9.75$ years, IQR $=7.46$ to 14.50 years). A total of 1989 women were enrolled in the trials compared with 504 men. The average proportion of women per trial was $80 \%$. All studies specified the source of the participants, who were recruited mainly using Internet-based promotion channels (e.g. Internet bulletin boards, established websites, and discussion groups). Fourteen studies used two comparator arms and one had three comparator arms (Hedborg 2011). Of the 14 studies that compared two arms, eight studies used waiting-list controls, three used treatment-as-usual controls, and three used an active control in which participants received educative text-based material or participated in an online discussion forum. The three comparator-armed study used an active control in comparison to two treatments. The first treatment group received a multimodal behaviour treatment and a $C D$ of muscular relaxation. The second treatment group received a hand massage in addition to the Internet-based programme and muscular relaxation $C D$. The control group received only the $C D$ of muscular relaxation (Hedborg 2011). Studies could not be analysed according to control type due to the small number of included trials.

Fourteen studies evaluated an Internet-delivered psychological therapy of a CBT orientation. One study used an acceptance commitment-based therapy (Buhrman 2013a). The mean duration of therapy was 11 weeks (range 3 to 46 weeks). The primary mode of therapy delivery for all studies was via computer. Two studies offered adjunctive structured telephone support (Buhrman 2004; Buhrman 2011). Two studies used the same pain management therapy, termed painACTION (Bromberg 2011; Chiauzzi 2010).
A further four studies were all from the same research group (Buhrman 2004; Buhrman 2011; Buhrman 2013; Buhrman 2013a). Data were available for extraction from all 15 included studies.

We present a summary of the characteristics of therapy and treatment content in Characteristics of included studies.

\section{Excluded studies}

Forty-nine studies did not meet the inclusion criteria for this study. Fourteen studies did not have chronic non-cancer pain as their primary pain condition (Anderson 2006; Chambers 2006; Cleeland 2011; Everitt 2010; Everitt 2013; Johns 2011; Kroenke 2010; Lorig 2006; Miller 2010; Oerlemans 2011; Premi 1993; Steel 2011; Taieb-Maimon 2012; Weingart 2008). Twelve studies did not use the Internet as their primary mode of treatment delivery (Allen 2008; Childs 2011; Greco 2004; Jennings 2008; Kjeken 2011; Kosterink 2010; Kristjansdottir 2011; Kristjansdottir 2013; Larsman 2010; Naylor 2008; Naylor 2010; Vonk Noordegraaf 2012). Nine studies did not evaluate a self-management psychological intervention (Bieber 2006; Bruce 2005; Fraenkel 2007; Hochlehnert 2006; Huffstutter 2007; Keulers 2007; Macedo 2012; Sandsjo 2010; Sciamanna 2006). Six studies were not randomised control trials (Borckardt 2004; de Bruijn-Kofman 1997; Jacobs 2013; LeboeufYde 2012; Leveille 2007; Spunt 1996). Three studies were excluded because the number of participants in any study arm was less than 20 (Andersson 2002; Brattberg 2006; Brattberg 2007). A further three studies were excluded because the intervention had insufficient psychotherapeutic content; these studies were evaluations of online peer discussion groups (Krein 2010; Leville 2009; Lorig 2002). Finally, two studies used non-inferiority designs (Kleiboer 2009; Russell 2011).

The initial identification of these studies using the search strategy outlined supports the criticism that a diversity of terminology is used to describe pain and therapies. We acknowledge that these judgements were often difficult to make and led to extensive discussions between review authors.

\section{Risk of bias in included studies}

'Risk of bias' summaries are shown in Figure 2 and Figure 3. Six 'risk of bias' categories were used: random sequence generation (selection bias), allocation concealment (selection bias), blinding of outcome assessment (detection bias), incomplete outcome data (attrition bias), selective reporting (reporting bias), and 'free from other bias'. Eight studies described a convincing method of randomisation and were judged to have a low risk of bias; a further six did not provide an adequate description and were judged to be unclear. One study did not describe randomisation and was judged to have a high risk of bias for random sequence generation. Five studies described a convincing method of allocation and had low risk of allocation bias; a further eight studies did not provide an adequate description and we judged them to be unclear. We rated two studies as high risk of allocation bias because group assignment was not concealed from the research assistants. Thirteen studies took assessments online and were therefore judged to have low risk of bias for blinding of outcome assessment. Two studies did not provide an adequate description of outcome assessment and were unclear. No studies were rated as high risk of outcome bias. Seven studies adequately reported attrition and found no significant differences between completers and noncompleters; these were judged to have a low risk of bias. Six were 
rated as unclear risk, mainly due to the non-reporting of differences between completers and non-completers. Two studies had high risk of bias for incomplete data due to statistical differences between completers and non-completers and a data management error that resulted in one outcome measure being unavailable for analysis. Eleven studies reported all outcomes and had a low risk of bias for selective reporting bias. A further four studies were rated to have high risk of selective reporting bias because data could not be extracted. No other sources of bias were found for the 15 studies included in the review. It is noteworthy that almost all outcomes were self-reported assessments, and so there were limited opportunities for influencing participants' scores. Consequently, most of our judgements of high risk of bias were because of inadequate reporting.

\section{Figure 2. 'Risk of bias' graph: review authors' judgements about each risk of bias item presented as percentages} across all included studies.

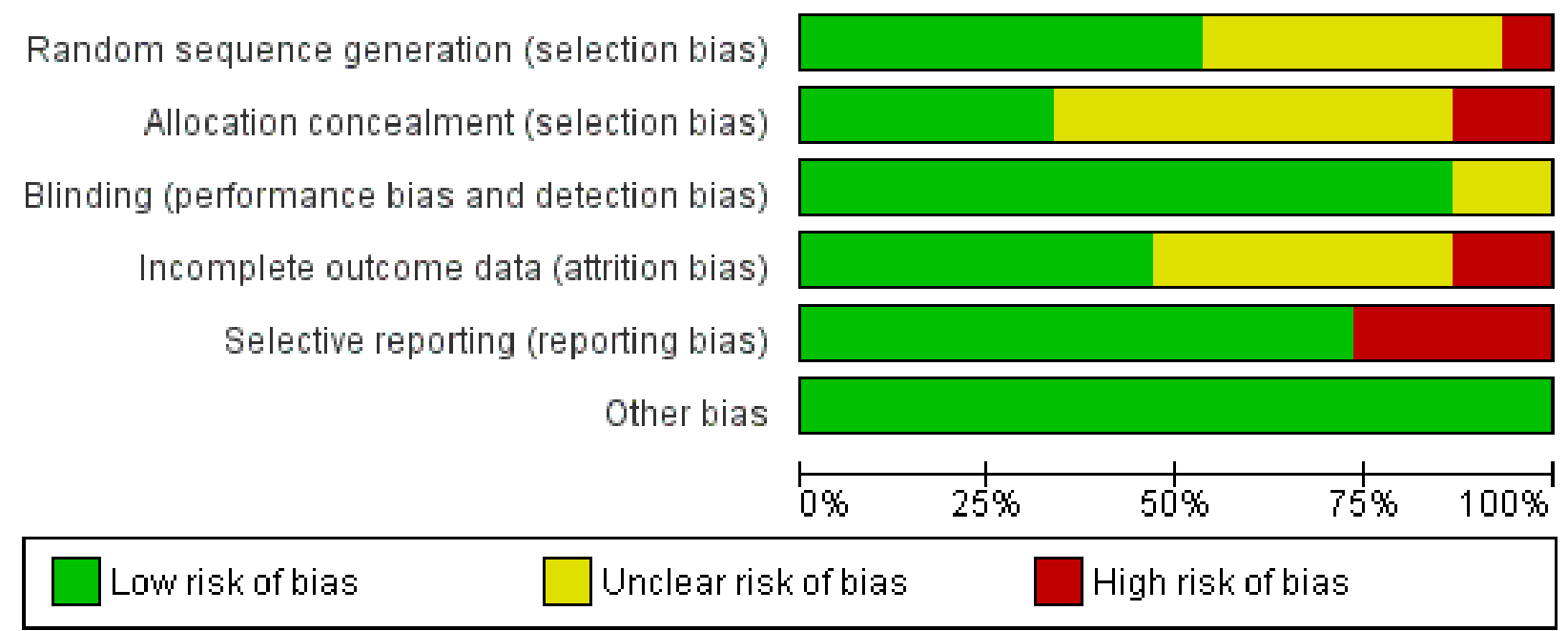


Figure 3. 'Risk of bias' summary: review authors' judgements about each risk of bias item for each included study.

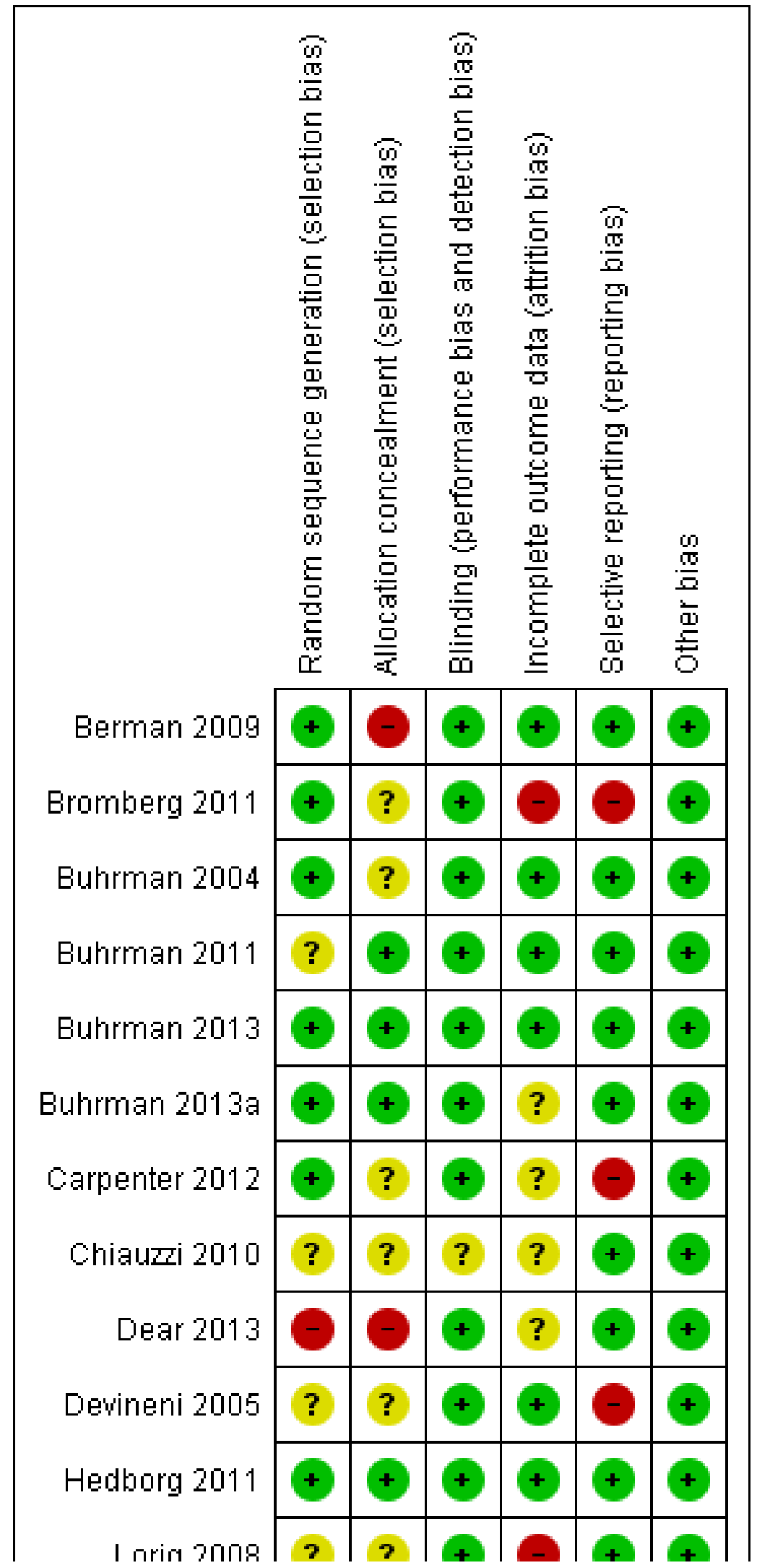


Figure 3. (Continued)

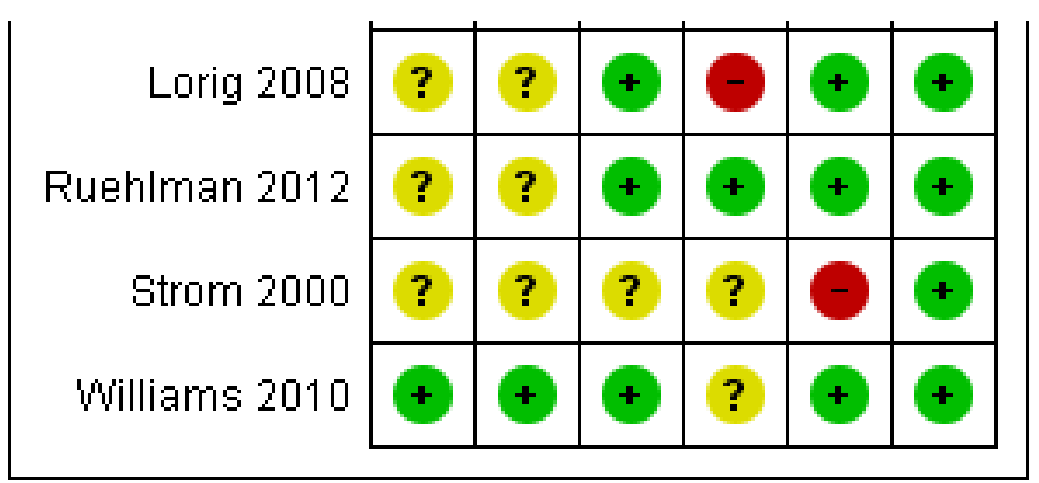

\section{Effects of interventions}

Data were analysed by two categories; headache conditions and non-headache conditions. For both categories, outcomes were analysed post-treatment and at follow-up. Note, no data could be presented for the secondary outcome 'treatment acceptability/ satisfaction' due to the lack of studies reporting this outcome quantitatively.

\section{Treatment versus control for headache conditions post- treatment}

Two studies with 131 participants were entered into an analysis of the effect of treatment on pain. The overall effect was beneficial for psychological therapies $(z=3.88, p<0.01$, RR $7.28,95 \% \mathrm{Cl} 2.67$ to $19.84, I^{2}=0 \%$; NNTB $=2.72$ ). Two studies with 241 participants were entered into an analysis of the effects of treatment on disability. The overall effect of psychological therapies was beneficial $(z=4.89, p<$ $0.01)$, with a moderate effect size (SMD $-0.65,95 \% \mathrm{Cl}-0.91$ to -0.39 , $\mathrm{I}^{2}=0 \%$ ) (Analysis 1.2). Four studies with 617 participants were entered into an analysis of the effects of treatment on depression; there was no clear evidence of benefit for psychological therapies $\left(\mathrm{z}=0.82, p>0.05, \mathrm{SMD}-0.26,95 \% \mathrm{Cl}-0.87\right.$ to $\left.0.36, \mathrm{I}^{2}=92 \%\right)$ (Analysis 1.3). Three studies with 546 participants were entered into an analysis of the effects of treatment on anxiety. Analyses showed there was no clear evidence of benefit for psychological therapies $(z=1.26, p>0.05, \mathrm{SMD}-0.48,95 \% \mathrm{Cl}-1.22$ to $0.27,12=94 \%)$ (Analysis 1.4). Only one study could be entered into an analysis of the effect of psychological therapies on quality of life; hence, no conclusions can be drawn. Only one study reported adverse outcomes (Devineni 2005): the study reported that $11.6 \%$ of treatment completers reported worsening of headache symptoms; the distribution between treatment and control groups was not reported.

Treatment versus control for headache conditions at follow-up
No data were available for the analysis of the effects of treatment on pain at follow-up. Only one study could be included for the analysis of the effects of treatment on disability at follow-up; hence, no conclusions can be drawn. Two studies with 425 participants were entered into an analysis of the effects of treatment on depression at follow-up and there was no clear evidence of benefit ( $z=0.94$, $p>0.05$, SMD $-1.03,95 \% \mathrm{Cl}-3.18$ to $1.12, \mathrm{I}^{2}=99 \%$ ) (Analysis 2.1). Two studies with 425 participants were entered into an analysis of the effects of treatment on anxiety at follow-up; there was no clear evidence of benefit $(z=1.42, p>0.05$, SMD $-0.46,95 \% \mathrm{Cl}-1.09$ to $0.18,1^{2}=88 \%$ ) (Analysis 2.2 ). Quality of life outcomes were not assessed by any study for headache conditions at follow-up.

\section{Treatment versus control for non-headache conditions post- treatment}

Eleven studies with 1785 participants were entered into an analysis of the effects of treatment on pain. The overall effect of treatment was beneficial for psychological therapies $(z=3.32, p<0.01)$, with a small effect size (SMD $-0.37,95 \% \mathrm{Cl}-0.59$ to $-0.15,12=77 \%$ ) (Analysis 3.1; Figure 4). Five studies with 1149 participants were entered into an analysis of the effects of treatment on disability. The overall effect was beneficial for psychological therapies ( $z$ $=3.26, p<0.01$ ), with a moderate effect size (SMD $-0.50,95 \%$ $\mathrm{Cl}-0.79$ to $-0.20,12=79 \%$ ) (Analysis 3.2; Figure 5). Nine studies with 1013 participants were entered into an analysis of the effects of treatment on depression. The overall effect was beneficial for psychological therapies with a small effect size $(z=2.41, p<0.05$, SMD $-0.19,95 \% \mathrm{Cl}-0.35$ to $-0.04,1^{2}=29 \%$ ) (Analysis 3.3). Ten studies with 1144 participants were entered into an analysis of the effects of treatment on anxiety. The overall effect for psychological therapies was beneficial, with a small effect size $(z=2.54, p<0.05$, SMD $-0.28,95 \% \mathrm{Cl}-0.49$ to $-0.06, \mathrm{I}^{2}=66 \%$ ) (Analysis 3.4). Three studies with 202 participants were entered into an analysis of the effects of treatment on quality of life. The overall effect did not show a benefit for psychological therapies $(z=1.88, p>0.05$, SMD -0.27 , $95 \% \mathrm{Cl}-0.54$ to $0.01, \mathrm{I}^{2}=0 \%$ ) (Analysis 3.5 ). 
Figure 4. Forest plot of comparison: 3 Non-headache post treatment, outcome: 3.1 Pain.

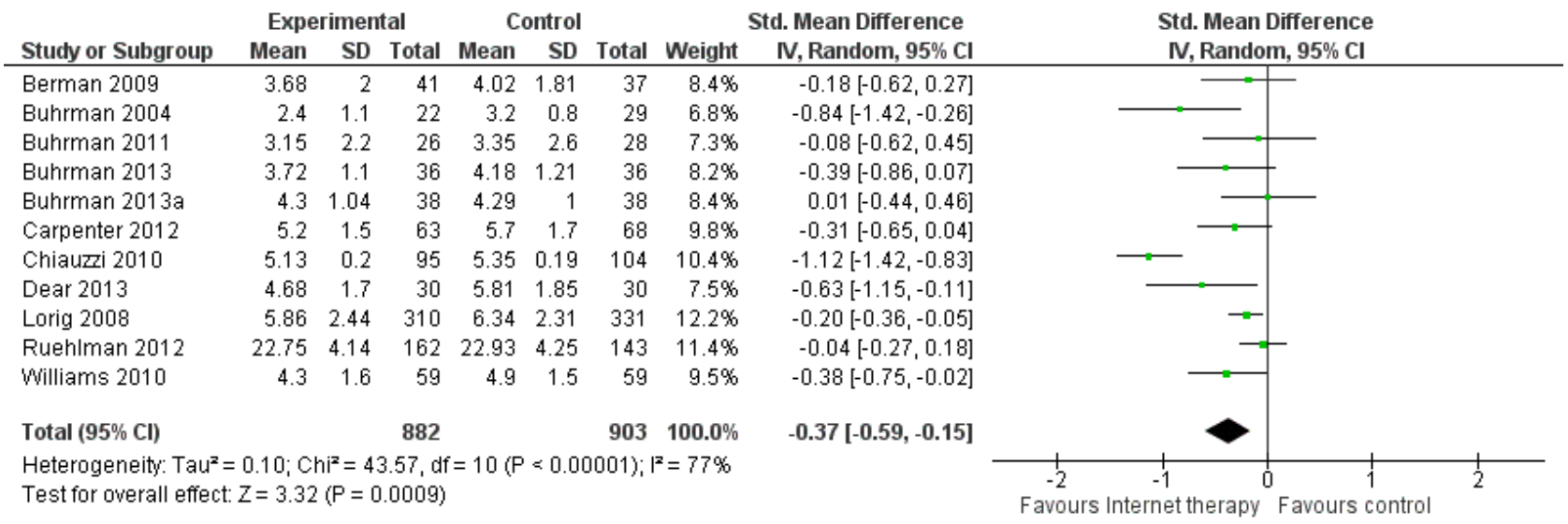

Figure 5. Forest plot of comparison: 3 Non-headache post treatment, outcome: 3.2 Disability.

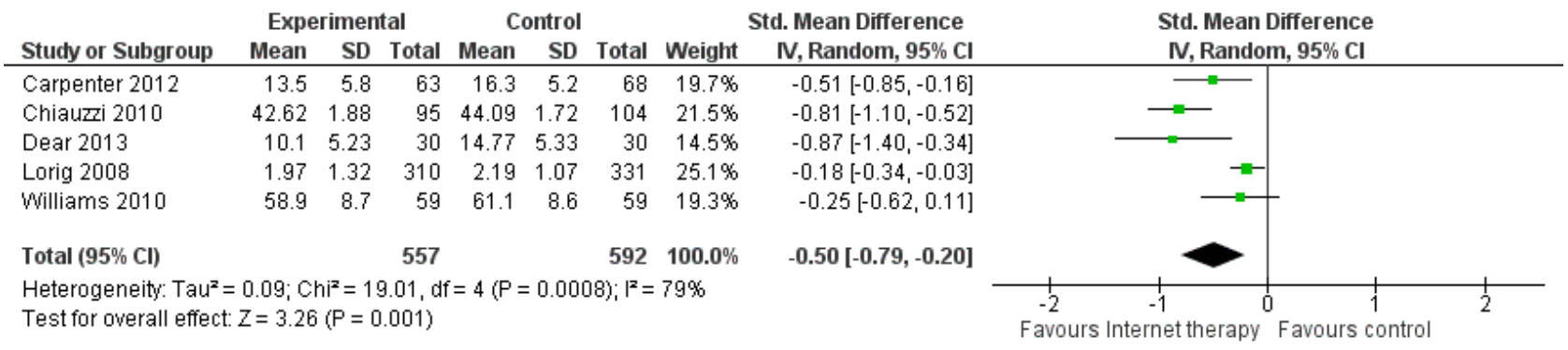

\section{Treatment versus control for non-headache conditions at follow-up}

Four studies with 1202 participants were entered into an analysis of the effects of treatment on pain at follow-up and the overall effect was not beneficial for psychological therapies $(z=1.34, p$ $>0.05$, SMD $-0.48,95 \% \mathrm{Cl}-1.18$ to $0.22, \mathrm{I}^{2}=96 \%$ ) (Analysis 4.1 ). Two studies with 850 participants were entered into an analysis of the effects of treatment on disability at follow-up and the overall effect for psychological therapies was beneficial $(z=2.17, p<0.05)$, with a small effect size (SMD $-0.15,95 \% \mathrm{Cl}-0.28$ to $\left.-0.01, \mathrm{I}^{2}=20 \%\right)$ (Analysis 4.2). Three studies with 551 participants were entered into an analysis of the effects of treatment on depression at followup and the overall effect did not show benefit for psychological therapies $\left(\mathrm{z}=0.80, p>0.05, \mathrm{SMD}-0.53,95 \% \mathrm{Cl}-1.84\right.$ to $0.78, \mathrm{I}^{2}$ $=98 \%$ ) (Analysis 4.3). Three studies with 551 participants were entered into an analysis of the effects of treatment on anxiety at follow-up. The overall effect was not beneficial for psychological therapies $\left(z=0.89, p>0.05\right.$, SMD $-0.39,95 \% \mathrm{Cl}-1.25$ to $0.47, \mathrm{I}^{2}=$ 95\%) (Analysis 4.4). Quality of life outcomes were not assessed by any study for non-headache conditions at follow-up.

\section{DISCUSSION}

\section{Summary of main results}

We investigated the efficacy of psychological therapies for chronic pain management delivered via the Internet, in comparison with active, treatment-as-usual, or waiting-list controls. Fifteen studies met the inclusion criteria for the review and data were available for extraction from all studies. Studies were categorised as headache or non-headache conditions. Eight analyses were conducted for each condition including four primary outcomes of pain, disability, depression, and anxiety. These were assessed at two time points: immediately post-treatment and at follow-up. There were also two secondary outcomes (quality of life and acceptability/satisfaction), which are discussed separately. For headache conditions, pain and disability improved immediately post-treatment. However, these findings should be treated with caution as only two studies could be included in each of the analyses. For non-headache conditions, pain, disability, depression, and anxiety improved immediately post-treatment, and disability also improved at follow-up. However, similar to headache findings, only two studies could be entered into the disability analyses at follow-up, and so this finding should also be interpreted cautiously.

Only one study reported adverse events; $11.6 \%$ of the completing participants with headache conditions reported a worsening of headache symptoms (Devineni 2005).

The overall attrition from studies was $17.4 \%$ on average (range 0 to 25). Reasons for attrition included health problems and illness, difficulty using a computer or being physically uncomfortable using a computer, and personal problems. For those who stayed in the study, overall compliance rates with treatment requirements (e.g. number of sessions completed) are not known. The planned analyses of secondary outcomes (quality of life and acceptability/ satisfaction) were limited because data were sparse. Only one study could be included in the analysis on quality of life in the headache condition so no analysis could be undertaken. No effect was found 
for the three studies that reported quality of life data immediately post-treatment in the non-headache condition. Internet-delivered psychological therapies are a novel method of treatment delivery, and acceptability and participant satisfaction are important yet neglected variables.

Internet-delivered psychological therapies had an impact on pain, disability, depression, and anxiety for non-headache conditions immediately post-treatment. Findings for the effect on all outcomes for headache conditions are minimal to limited. It should be acknowledged that the small effect sizes and lack of effect for depression and anxiety may be due to the lack of sensitivity to change: the baseline levels of depression and anxiety were low for the participants included in this review. This observation raises the question of the appropriateness of mental health interventions for individuals with chronic pain. In future studies/updates we might require a revised inclusion criterion requiring participants to be sufficiently depressed, anxious, and/or disabled.

In contrast to immediate post-treatment evaluations, few studies included follow-up assessments. Our conclusions regarding the effects of psychological therapies delivered via the Internet on longer-term symptom improvements, particularly with regards to pain, are therefore limited. There was no cut-off for pain severity in the inclusion criteria for this review and participants tended to have moderate pain ratings. It is acknowledged that different findings may have been obtained if studies had included participants with severe pain.

There are some limitations associated with the current set of primary studies included. A high level of heterogeneity was reported for some outcomes, which may have introduced an overestimation of effect. This could be attributed to the following reasons: first, most studies recruit people from the general population who self-select and volunteer to participate. The inclusion of such populations may limit the applicability of findings to clinical populations, and may introduce floor effects on some measures. Second, we combined studies with different comparison arms of treatments as there are not yet sufficient data within the same comparison group. Third, different measures were combined within the same outcome domain. Studies with a standard placebo control are needed. It is also not possible to state whether treatment is more effective than completing an active control (Williams 2012). Some have suggested that individuals in wait-list control groups do not take action to diminish painrelated problems during their waiting period because participants are expectant of future professional support (Cuijpers 2008). In future updates, when data allow, we will seek to compare treatments within their class of comparison treatment (e.g. placebo, treatment-as-usual). Internet-delivered treatment offers the possibility of matching treatment intensity to need, and to shape content to need, but we do not have data from this review that enable us to make any evidence-based comments on these possibilities. Finally, no analysis of adverse effects was possible, and no analysis of treatment expectations, satisfaction, or compliance was possible.

\section{Overall completeness and applicability of evidence}

Studies in this review were dominated by cognitive behavioural and behavioural treatments. The content of therapies reviewed was fairly homogeneous, with most including cognitive skill building components (e.g. problem solving skills training) as well as applied components (e.g. relaxation training). As found in the review by Williams 2012, which investigated face-to-face psychological therapies in adults with chronic pain (excluding headache), there was an apparent disjunction between the stated aims of treatment, actual treatment content and outcomes measured. Most studies did not include a comprehensive justification of treatment rationale and it was not always clear how the outcomes assessed linked to the intended aims of treatment.

We excluded a number of studies because of the absence of content that could be considered psychological. There are many ways in which the Internet and technology could be used to further the overall goal of independent management of pain. A broader consideration of developments in telehealth and chronic pain would capture work in sensing and assessment, mobile health monitoring, virtual reality including immersive environments, games for pain, and education, to name a few (Keogh 2010). Clearer information is required regarding whether therapies are designed to augment, replace, or improve on face-to-face psychological therapy, and in what way the proposed mechanism of improving self-management is psychological.

\section{Agreements and disagreements with other studies or reviews}

The findings are consistent with other systematic reviews in this field. Similar effects for have been found for pain outcomes (Bender 2011; Cuijpers 2008; Macea 2010) and activity limitation (Bender 2011). Similar to the findings in this review for nonheadache conditions, systematic reviews have found reductions in depression and anxiety scores after CBT was delivered via the Internet (Griffiths 2010; Spek 2007). The types of therapies that met the inclusion criteria varied across reviews. In addition to CBT interventions, Bender 2011 assessed peer-support programmes (e.g. social networking programmes) and clinical visit supports, although they found insufficient evidence for Internetbased clinical support interventions. Cuijpers 2008 considered interventions that consisted of online contact between therapist/ moderator and participant, where the Internet facilitated contact, rather than acting as the primary intervention itself. This review, unlike the other three, excluded child studies.

This review can be directly compared to Williams 2012, from which it was partly born. The average age and gender ratio in both reviews were very similar (mean $=48$ years, SD $=9$ years, women $=71 \%$ in Williams 2012, compared with mean $=47$ years, SD $=8$ years, women $=80 \%$ in the current review). Participants were recruited via different methods. Williams 2012 found that most participants were recruited via healthcare settings (e.g. pain rehabilitation clinics, rheumatology clinics, and the community). However, this review found that most participants volunteered after seeing an advert on an Internet forum. The findings of this review also were similar to the face-to-face therapies reviewed by Williams 2012. First, Williams 2012 found that pain, disability, mood (depression), and catastrophising in adults with chronic pain (excluding headache) improved immediately post-treatment. Similarly, this review revealed positive effects for pain, disability, depression, and anxiety post-treatment for individuals with nonheadache conditions. However, the results differed at follow-up. Williams 2012 found an effect on mood to be maintained at follow-up. No such effect was found in this review. However, this review found disability to be maintained at follow-up, although the analysis included only two studies and so should be interpreted 
with caution. There are fewer studies included in this review $(\mathrm{N}=$ 15) compared to Williams $2012(\mathrm{~N}=35)$ and the overall number of participants was also fewer $(\mathrm{N}=2012)$ compared to Williams 2012 $(\mathrm{N}=4788)$.

\section{AUTHORS' CONCLUSIONS \\ Implications for practice}

Internet-delivered cognitive behavioural therapy (CBT) for the management of chronic pain in adults may be effective for the short-term management of pain, disability, depression, and anxiety in individuals with chronic non-headache pain conditions, but there is currently limited evidence for their effectiveness for headache pain and disability, and no evidence for their effectiveness on depression and anxiety in individuals with chronic headache conditions. On average, participants entering trials of Internet-delivered treatment are mildly disabled and distressed. No conclusions can be made for treatments other than CBT. We do not know if these treatments are associated with adverse events and we do not know how satisfied participants are with these treatments.

\section{Implications for research}

Delivering cognitive and behaviour change therapies via the Internet without an expert health professional managing real-time delivery is possible. However, the exact content of therapy, the characteristics of the treatment method, and the methods by which individuals are selected for such therapy are not known. In essence we do not know what can work for whom and in what context. This research is at a very early stage of development and the studies reviewed here can usefully be considered immature. Two areas of research are needed.

First, the most effective method of face-to-face treatment identified in Williams 2012 should be adapted for delivery via the Internet using the most effective method of evaluation: the placebo- controlled RCT. Future RCTs should have the following critical features:

1. Be properly powered to detect meaningful changes in the primary outcomes measured (approximate $n=300$ );

2. Use a placebo therapy as the primary comparator;

3. Make attempts to blind both participants and investigators to treatment selection;

4. Measure adverse effects, participant satisfaction, adherence to treatment, and reasons for attrition;

5. Enrol only participants with moderate-to-severe pain, disability, or distress;

6. Select domains and outcome measurement tools commensurate with IMMPACT guidance (Dworkin 2005).

Second, further pre-evaluation studies are needed to examine critical aspects of Internet delivery of therapeutic communication, such as, but not limited to the following.

1. Can therapeutic alliance be achieved with non-human objects/ systems, and is it necessary to deliver behaviour change?

2. Can novel aspects of Internet systems be used therapeutically (e.g. immersion technology, multi-agent connections, remote sensing)?

3. Can Internet treatments augment traditional real-time human interaction and can limited human interaction (e.g. skills practice review or telephone support) augment Internetdelivered therapies?

Research is needed in both fundamental aspects of Internet communication: persuasion and therapy. However, whilst this research develops, we believe there is a case for efficacy studies on the current most promising treatments for adults with chronic pain.

\section{A CKN OWLEDGEMENTS}

We would like to thank Joanne Abbott for designing and running the search for this review. 


\section{R E F E R E N C E S}

\section{References to studies included in this review}

Berman 2009 \{published data only\}

Berman RLH, Iris MA, Bode R, Drengenberg C. The effectiveness of an online mind-body intervention for older adults with chronic pain. The Journal of Pain 2009;10(1):68-79.

\section{Bromberg 2011 \{published data only\}}

Bromberg J, Wood ME, Black RA, Surette DA, Zacharoff KL, Chiauzzi EJ. A randomized trial of a web-based intervention to improve migraine self-management and coping. Headache 2011;52(2):244-61.

\section{Buhrman 2004 \{published data only\}}

Buhrman M, Faltenhag S, Strom L, Andersson G. Controlled trial of Internet-based treatment with telephone support for chronic back pain. Pain 2004;111(3):368-77.

\section{Buhrman 2011 \{published data only\}}

Buhrman M, Nilsson-Ihrfeldt E, Jannert M, Strom L, Andersson G. Guided internet-based cognitive behavioural treatment for chronic back pain reduces pain catastrophizing: a randomized controlled trial. Journal of Rehabilitation Medicine 2011;43(6):500-5.

\section{Buhrman 2013 \{published data only\}}

Buhrman M, Fredriksson A, Edstrom G, Shafiei D, Tarnqvist C, Ljotsson B, et al. Guided internet-delivered cognitive behavioural therapy for chronic pain patients who have residual symptoms after rehabilitation treatment: randomized controlled trial. European Journal of Pain 2013;17(5):753-65.

Buhrman 2013a \{published data only\}

Buhrman M, Skoglund A, Husell J, Bergstrom K, Gordh T, Hursti T, et al. Guided internet-delivered acceptance and commitment therapy for chronic pain patients: a randomized controlled trial. Behaviour Research and Therapy 2013;51(6):307-15.

\section{Carpenter 2012 \{published data only\}}

Carpenter KM, Stoner SA, Mundt JM, Stoelb B. An online selfhelp CBT intervention for chronic lower back pain. The Clinical Journal of Pain 2012;28(1):14-22.

\section{Chiauzzi 2010 \{published data only\}}

Chiauzzi E, Pujol LA, Wood M, Bond K, Black R, Yiu E, et al. painACTION-back pain: a self-management website for people with chronic back pain. Pain Medicine 2010;11(7):1044-58.

\section{Dear 2013 \{published data only\}}

Dear BF, Titov N, Perry KN, Jonston L, Wootton BM, Terides MD, et al. The Pain Course: a randomised controlled trial of a clinician-guided internet-delivered cognitive behaviour therapy program for managing chronic pain and emotional well-being. Pain 2013;154(6):942-50.
Devineni 2005 \{published data only\}

Devineni T, Blanchard EB. A randomized controlled trial of internet-delivered, self-help treatment for chronic benign headache. Behaviour Research and Therapy 2005;43(3):277-92.

Hedborg 2011 \{published data only\}

Hedborg K, Muhr C. Multimodal behavioral treatment of migraine: an Internet-administered, randomized, controlled trial. Upsala Journal of Medical Sciences 2011;116(3):169-86.

Lorig 2008 \{published data only\}

Lorig KR, Ritter PL, Laurent DD, Plant K. The internet-based arthritis self-management program: a one-year randomized trial for patients with arthritis or fibromyalgia. Arthritis and Rheumatism 2008;59(7):1009-17.

Ruehlman 2012 \{published data only\}

Ruehlman LS, Karoly P, Enders C. A randomized controlled evaluation of an online chronic pain self management program. Pain 2012;153(2):319-30.

\section{Strom 2000 \{published data only\}}

Strom L, Pettersson R, Andersson G. A controlled trial of self-help treatment of recurrent headache conducted via the Internet. Journal of Consulting and Clinical Psychology 2000;68(4):722-7.

\section{Williams 2010 \{published data only\}}

Williams DA, Kuper D, Segar M, Mohan N, Sheth M, Clauw DJ. Internet-enhanced management of fibromyalgia: a randomized controlled trial. Pain 2010;151(3):694-702.

\section{References to studies excluded from this review}

Allen 2008 \{published data only\}

Allen M, lezzoni LI, Huang A, Huang L, Leveille SG. Improving patient-clinician communication about chronic conditions: description of an internet-based nurse E-coach intervention. Nursing Research 2008;57(2):107-12.

\section{Anderson 2006 \{published data only\}}

Anderson KO, Cohen MZ, Mendoza TR, Guo H, Harle MT, Cleeland CS. Brief cognitive-behavioral audiotape interventions for cancer-related pain: immediate but not long-term effectiveness. Cancer 2006;107(1):207-14.

\section{Andersson 2002 \{published data only\}}

Andersson G, Lundstrom P, Strom L. Internet-based treatment of headache: does telephone contact add anything?. Headache 2003;43(4):353-61.

\section{Bieber 2006 \{published data only\}}

Bieber C, Muller KG, Blumenstiel K, Schneider A, Richter A, Wilke $S$, et al. Long-term effects of a shared decision-making intervention on physician-patient interaction and outcome in fibromyalgia. A qualitative and quantitative 1 year follow-up of a randomized controlled trial. Patient Education and Counseling 2006;63(3):357-66 


\section{Borckardt 2004 \{published data only\}}

Borckardt JJ, Younger J, Winkel J, Nash MR, Shaw D. The computer-assisted cognitive/imagery system for use in the management of pain. Pain Research \& Management 2004;9(3):157-62.

\section{Brattberg 2006 \{published data only\}}

Brattberg G. Internet-based rehabilitation for individuals with chronic pain and burnout: a randomized trial. International Journal of Rehabilitation Research 2006;29(3):221-7.

\section{Brattberg 2007 \{published data only\}}

Brattberg G. Internet-based rehabilitation for individuals with chronic pain and burnout II: a long-term followup. International Journal of Rehabilitation Research 2007;30(3):231-4.

\section{Bruce 2005 \{published data only\}}

Bruce B, Lorig K, Laurent D, Ritter P. The impact of a moderated e-mail discussion group on use of complementary and alternative therapies in subjects with recurrent back pain. Patient Education and Counseling 2005;58(3):305-11.

\section{Chambers 2006 \{published data only\}}

Chambers A, Hennessy E, Powel-Tuck J. Longitudinal trends in quality of life after starting home parenteral nutrition: a randomised controlled study of telemedicine. Clinical Nutrition 2006;25(3):505-14.

\section{Childs 2011 \{published data only\}}

Childs JD, Teyhen DS, Van Wyngaarden JJ, Dougherty BF, Ladislas BJ, Helton GL, et al. Predictors of web-based followup response in the Prevention Of Low Back Pain In The Military Trial (POLM). BMC Musculoskeletal Disorders 2011;12(1):132.

\section{Cleeland 2011 \{published data only\}}

Cleeland CS, Wang XS, Shi Q, Mendoza TR, Wright SL, Berry MD, et al. Automated symptom alerts reduce postoperative symptom severity after cancer surgery: a randomized controlled clinical trial. Journal of Clinical Oncology 2011;29(8):994-1000.

\section{de Bruijn-Kofman 1997 \{published data only\}}

de Bruijn-Kofman AT, Van De Wiel H, Groenman NH, Sorbi MJ, Klip E. Effects of a mass media behavioral treatment for chronic headache: a pilot study. Headache 1997;37(7):415-20.

\section{Everitt 2010 \{published data only\}}

Everitt HA, Moss-Morris RE, Sibelli A, Tapp L, Coleman NS, Yardley $L$, et al. Management of irritable bowel syndrome in primary care: feasibility randomised controlled trial of mebeverine, methylcellulose, placebo and a patient selfmanagement cognitive behavioural therapy website. (MIBS trial). BMC Gastroenterology 2010;10(1):136.

\section{Everitt 2013 \{published data only\}}

Everitt H, Moss-Morris R, Sibelli A, Tapp L, Coleman N, Yardley L, et al. Management of irritable bowel syndrome in primary care: the results of an exploratory randomised controlled trial of mebeverine, methylcellulose, placebo and a self-management website. BMC Gastroenterology 2013;13(1):68.

\section{Fraenkel 2007 \{published data only\}}

Fraenkel L, Rabidou N, Wittink D, Fried T. Improving informed decision-making for patients with knee pain. The Journal of Rheumatology 2007;34(9):1894-8.

\section{Greco 2004 \{published data only\}}

Greco CM, Rudy TE, Manzi S. Effects of a stress-reduction program on psychological function, pain, and physical function of systemic lupus erythematosus patients: a randomized controlled trial. Arthritis and Rheumatism 2004;51(4):625-34.

\section{Hochlehnert 2006 \{published data only\}}

Hochlehnert A, Richter A, Bludau HB, Bieber C, Blumenstiel K, Mueller $\mathrm{K}$, et al. A computer-based information-tool for chronic pain patients. Computerized information to support the process of shared decision-making. Patient Education and Counseling 2006;61(1):92-8.

\section{Huffstutter 2007 \{published data only\}}

Huffstutter J, Craig WD, Schimizzi G, Harshbarger J, Lisse J, Kasle S, et al. A multicenter, randomized, open study to evaluate the impact of an electronic data capture system on the care of patients with rheumatoid arthritis. Current Medical Research and Opinion 2007;23(8):1967-79.

\section{Jacobs 2013 \{published data only\}}

Jacobs K, Foley G, Punnett L, Hall V, Gore R, Brownson E, et al. University students' notebook computer use: lessons learned using e-diaries to report musculoskeletal discomfort. Ergonomics 2013;54(2):206-19.

\section{Jennings 2008 \{published data only\}} Jennings MB, Lesczczynski C, Goodwin S. The safety and efficacy of Pain Checker socks in the treatment of mild-tomoderate foot pain: a clinical trial. Journal of the American Podiatric Medical Association 2008;98(4):278-82.

\section{Johns 2011 \{published data only\}}

Johns SA, Kroenke K, Theobald DE, Wu J, Tu W. Telecare management of pain and depression in patients with cancer: patient satisfaction and predictors of use. The Journal of Ambulatory Care Management 2011;34(2):126-39.

\section{Keulers 2007 \{published data only\}}

Keulers BJ, Welters CFM, Spauwen PHM, Houpt P. Can faceto-face patient education be replaced by computer-based patient education? A randomised trial. Patient Education and Counseling 2007;67(1-2):176-82.

\section{Kjeken 2011 \{published data only\}}

Kjeken I, Darre S, Smedslund G, Hagen KB, Nossum R. Effect of assistive technology in hand osteoarthritis: a randomised controlled trial. Annals of the Rheumatic Diseases 2011;70(8):1447-52.

\section{Kleiboer 2009 \{published data only\}}

Kleiboer A, Sorbi M, Merelle S, Passchier J, van Doornen L. Utility and preliminary effects of online digital assistance (ODA) for behavioral attack prevention in migraine. Telemedicine Journal and e-Health 2009;15(7):682-90. 
Kosterink 2010 \{published data only\}

Kosterink SM, Huis in 't Veld RM, Cagnie B, Hasenbring M, Vollenbroek-Hutten MM. The clinical effectiveness of a myofeedback-based teletreatment service in patients with nonspecific neck and shoulder pain: a randomized controlled trial. Journal of Telemedicine and Telecare 2010;16(6):316-21.

\section{Krein 2010 \{published data only\}}

Krein S, Metreger T, Kadri R, Hughes M, Kerr EA, Piette JD, et al. Veterans walk to beat back pain: study rationale, design and protocol of a randomized trial of a pedometer-based internet mediated intervention for patients with chronic low back pain.. BMC Musculoskeletal Disorders 2010;11(1):205.

\section{Kristjansdottir 2011 \{published data only\}}

Kristjansdottir OB, Fors EA, Eide E, Finset A, Van Dulmen S, Wigers $\mathrm{SH}$, et al. Written online situational feedback via mobile phone to support self-management of chronic widespread pain: a usability study of a Web-based intervention. BMC Musculoskeletal Disorders 2011;12(1):51.

\section{Kristjansdottir 2013 \{published data only\}}

Kristjansdottir OB, Fors EA, Eide E, Finset A, Stensrud T, van Dulmen S, et al. A smartphone-based intervention with diaries and therapist-feedback to reduce catastrophizing and increase functioning in women with chronic widespread pain: randomized controlled trial. Journal of Medical Internet Research 2013;15(1):e5.

Kristjansdottir OB, Fors EA, Eide E, Finset A, Stensrud TL, van Dulmen $S$, et al. A smartphone-based intervention with diaries and therapist feedback to reduce catastrophizing and increase functioning in women with chronic widespread pain. part 2: 11-month follow-up results of a randomized trial. Journal of Medical Internet Research 2013;15(3):e72.

\section{Kroenke 2010 \{published data only\}}

Kroenke K, Theobald D, Wu J, Norton K, Morrison G, Carpenter J, Tu W. Effect of telecare management on pain and depression in patients with cancer: a randomized trial. JAMA 2010;304(2):163-71.

\section{Larsman 2010 \{published data only\}}

Larsman P, Hasenbring M, Sandsjo L, Huis in 't Veld RM, Witvrouw E, Kosterink SM, et al. Prognostic factors for the effect of a myofeedback-based teletreatment service. Journal of Telemedicine and Telecare 2010;16(6):336-43.

\section{Leboeuf-Yde 2012 \{published data only\}}

Leboeuf-Yde C, Jensen RK, Axen I. Absence of low back pain in patients followed weekly over one year with automated text messages. Chiropractic \& Manual Therapies 2012;20(9):1-7.

\section{Leveille 2007 \{published data only\}}

Leveille SG, Huang A, Tsai SB, Weingart SN, lezzoni LI. Screening for chronic conditions using a patient internet portal: recruitment for an internet-based primary care intervention. Journal of General Internal Medicine 2007;23(4):472-5.
Leville 2009 \{published data only\}

Leveille SG, Huang A, Tsai SB, Allen M, Weingart SN, lezzoni LI. Health coaching via an internet portal for primary care patients with chronic conditions: a randomized controlled trial. Medical Care 2009;47(1):41-7.

\section{Lorig 2002 \{published data only\}}

Lorig KR, Laurent DD, Deyo RA, Marnell ME, Minor MA, Ritter PL. Can a Back Pain E-mail Discussion Group improve health status and lower health care costs?: A randomized study. Archives of Internal Medicine 2002;162(7):792-6.

Lorig 2006 \{published data only\} Lorig KR, Ritter PL, Laurent DD, Plant K. Internet-based chronic disease self-management: a randomized trial. Medical Care 2006;44(11):964-71.

\section{Macedo 2012 \{published data only\}}

Macedo LG, Maher CG, Latimer J, McAuley JH. Feasibility of using short message service to collect pain outcomes in a low back pain clinical trial. Spine 2012;37(13):1151-1155.

\section{Miller 2010 \{published data only\}}

Miller DM, Moore SM, Fox RJ, Atreja A, Fu AZ, Lee JC, et al. Webbased self-management for patients with multiple sclerosis: a practical, randomized trial. Telemedicine Journal and e-Health 2010;17(1):5-13.

\section{Naylor 2008 \{published data only\}} Naylor MR, Keefe FJ, Brigidi B, Naud S, Helzer JE. Therapeutic Interactive Voice Response for chronic pain reduction and relapse prevention. Pain 2008;134(3):335-45.

\section{Naylor 2010 \{published data only\}}

Naylor MR, Naud S, Keefe FJ, Helzer JE. Therapeutic Interactive Voice Response (TIVR) to reduce analgesic medication use for chronic pain management. The Journal of Pain 2010;11(12):1410-9.

\section{Oerlemans 2011 \{published data only\}}

Oerlemans S, van Cranenburgh O, Herremans PJ, Spreeuwenberg P, van Dulmen S. Intervening on cognitions and behavior in irritable bowel syndrome: a feasibility trial using PDAs. Journal of Psychosomatic Research 2011;70(3):267-77.

\section{Premi 1993 \{published data only\}}

Premi J, Shannon S. Randomized controlled trial of a combined video-workbook educational program for CME. Academic Medicine 1993;68(10 Suppl):S13-5.

\section{Russell 2011 \{published data only\}}

Russell TG, Buttrum P, Wootton R, Jull GA. Internet-based outpatient telerehabilitation for patients following total knee arthroplasty: a randomized controlled trial. The Journal of Bone and Joint Surgery 2011;93(2):113-20.

\section{Sandsjo 2010 \{published data only\}}

Sandsjo L, Larsman P, Huis in 't Veld RM, VollenbroekHutten MM. Clinical evaluation of a myofeedback-based teletreatment service applied in the workplace: a randomized 
controlled trial. Journal of Telemedicine and Telecare 2010;16(6):329-35.

\section{Sciamanna 2006 \{published data only\}}

Sciamanna CN, Nicholson RA, Lofland JH, Manocchia M, Mui S, Hartman CW. Effects of a website designed to improve the management of migraines. Headache 2006;46(1):92-100.

\section{Spunt 1996 \{published data only\}}

Spunt BS, Deyo RA, Taylor VM, Leek KM, Goldberg HI, Mulley AG. An interactive videodisc program for low back pain patients. Health Education Research 1996;11(4):535-41.

\section{Steel 2011 \{published data only\}}

Steel J, Geller DA, Tsung A, Marsh JW, Dew MA, Spring M, et al. Randomized controlled trial of a collaborative care intervention to manage cancer-related symptoms: lessons learned. Clinical Trials 2011;8(3):298-310.

\section{Taieb-Maimon 2012 \{published data only\}}

Taieb-Maimon M, Cwikel J, Shapira B, Orenstein I. The effectiveness of a training method using self-modeling webcam photos for reducing musculoskeletal risk among office workers using computers. Applied Ergonomics 2012;43(2):376-85.

\section{Vonk Noordegraaf 2012 \{published data only\}}

Vonk Noordegraaf A, Huirne JA, Brolmann HA, Emanuel MH, van Kesteren PJ, Kleiverda G, et al. Effectiveness of a multidisciplinary care program on recovery and return to work of patients after gynaecological surgery; design of a randomized controlled trial. BMC Health Services Research 2012;12(1):29.

\section{Weingart 2008 \{published data only\}}

Weingart SN, Hamrick HE, Tutkus S, Carbo A, Sands DZ, Tess A, et al. Medication safety messages for patients via the web portal: the MedCheck intervention. International Journal of Medical Informatics 2008;77(3):161-8.

\section{Additional references}

\section{Bailey 2010}

Bailey JV, Murray E, Rait G, Mercer CH, Morris RW, Peacock R, et al. Interactive computer-based interventions for sexual health promotion. Cochrane Database of Systematic Reviews 2010, Issue 9. [DOI: 10.1002/14651858.CD006483.pub2]

\section{Bender 2011}

Bender JL, Radhakrishnan A, Diorio C, Englesakis M, Jadad AR. Can pain be managed through the Internet? A systematic review of randomized controlled trials. Pain 2011;152(8):1740-50.

\section{Black 2011}

Black AD, Car J, Pagliari C, Anandan C, Cresswell K, Bokun T, et al. The impact of eHealth on the quality and safety of health care: a systematic overview. PLoS Medicine 2011;8(1):e1000387. [DOI: 10.1371/journal.pmed.1000387]

\section{Bodenheimer 2002}

Bodenheimer T, Lorig K, Holman H, Grumbach K. Patient self-management of chronic disease in primary care. JAMA 2002;288(19):2469-75.

\section{Breivik 2006}

Breivik H, Collet B, Ventafridda V, Cohen R, Gallacher D. Survey of chronic pain in Europe: prevalence, impact on daily life, and treatment. European Journal of Pain 2006;10(4):287-333.

\section{Civljak 2013}

Civljak M, Stead LF, Hartmann-Boyce J, Sheikh A, Car J. Internet-based interventions for smoking cessation. Cochrane Database of Systematic Reviews 2013, Issue 7. [DOI: 10.1002/14651858.CD007078.pub4]

\section{Cuijpers 2008}

Cuijpers P, van Straten A, Andersson G. Internet-administered cognitive behaviour therapy for health problems: a systematic review. Journal of Behavioral Medicine 2008;31(2):169-77.

\section{Currell 2000}

Currell R, Urquhart C, Wainwright P, Lewis R. Telemedicine versus face to face patient care: effects on professional practice and health care outcomes. Cochrane Database of Systematic Reviews 2000, Issue 2. [DOI: 10.1002/14651858.CD002098]

\section{Dworkin 2005}

Dworkin RH, Turk DC, Farrar JT, Haythornthwaite JA, Jensen MP, Katz NP, et al. Core outcome domains for chronic pain clinical trials: IMMPACT recommendations. Pain 2005;113(1-2):9-19.

\section{Fu 2003}

Fu D, Fu H, McGowan P, Sehn YE, Zhu L, Yang H, et al. Implementation and quantitative evaluation of chronic disease self-management programme in Shanghai, China: randomized controlled trial. Bulletin of the World Health Organization 2003;81(3):174-82

Gatchel 2007

Gatchel RJ, Peng YB, Peters ML, Fuchs PN, Turk DC. The biopsychosocial approach to chronic pain: scientific advances and future directions. Psychological Bulletin 2007;133(4):581-624.

\section{Griffiths 2010}

Griffiths KM, Farrer L, Christensen H. The efficacy of internet interventions for depression and anxiety disorders: a review of randomised controlled trials. The Medical Journal of Australia 2010;192(11 (Suppl)):S4-11.

\section{Hardiker 2011}

Hardiker NR, Grant MJ. Factors that influence public engagement with eHealth: a literature review. International Journal of Medical Informatics 2011;80(1):1-12.

\section{Higgins 2011}

Higgins JPT, Green S (editors). Cochrane Handbook for Systematic Reviews of Interventions Version 5.1.0 [updated March 2011]. The Cochrane Collaboration, 2011. Available from www.cochrane-handbook.org. 


\section{Jennett 2003}

Jennett PA, Affleck Hall L, Hailey D, Ohinmaa A, Anderson C, Thomas R, et al. The socio-economic impact of telehealth: a systematic review. Journal of Telemedicine and Telecare 2003;9(6):311-20.

\section{Jordan 2007}

Jordan JE, Osborne RH. Chronic disease self-management education programs: challenges ahead. The Medical Journal of Australia 2007;186(2):84-7.

\section{Keogh 2010}

Keogh E, Rosser BA, Eccleston C. e-Health and chronic pain management: current status and developments. Pain 2010;151(1):18-21.

\section{King 2011}

King S, Chambers CT, Huguet A, MacNevin RC, McGrath PJ, Parker $L$, et al. The epidemiology of chronic pain in children and adolescents revisited: a systematic review. Pain 2011;152(12):2729-38.

\section{Lewis 2004}

Lewis R, Dixon J. Rethinking management of chronic diseases. BMJ 2004;328(7433):220-2.

\section{Macea 2010}

Macea DD, Gajos K, Calil YAD, Fregni F. The efficacy of webbased cognitive behavioural interventions for chronic pain: a systematic review and meta-analysis. The Journal of Pain 2010;11(10):917-29.

\section{Martin 2008}

Martin S, Kelly G, Kernohan WG, McCreight B, Nugent C. Smart home technologies for health and social care support. Cochrane Database of Systematic Reviews 2008, Issue 4. [DOI: 10.1002/14651858.CD006412.pub2]

\section{McLean 2010}

McLean S, Chandler D, Nurmatov U, Liu J, Pagliari C Car J, et al. Telehealthcare for asthma. Cochrane Database of Systematic Reviews 2010, Issue 10. [DOI: 10.1002/14651858.CD007717.pub2]

\section{McLean 2011}

McLean S, Protti D, Sheikh A. Telehealthcare for long term conditions. BMJ 2011;342:374-8.

\section{Pal 2013}

Pal K, Eastwood SV, Michie S, Farmer AJ, Barnard ML, Peacock R, et al. Computer-based diabetes self-management interventions for adults with type 2 diabetes mellitus.

\section{CHARACTERISTICS OF STUDIES}

Characteristics of included studies [ordered by study ID]
Cochrane Database of Systematic Reviews 2013, Issue 3. [DOI: 10.1002/14651858.CD008776.pub2]

\section{Palermo 2009}

Palermo TM, Wilson AC, Peters M, Lawandowski A, Somhegyi H. Randomized controlled trial of an internet-delivered family cognitive-behavioral therapy intervention for children and adolescents with chronic pain. Pain 2009;146(1-2):205-13.

\section{RevMan 2011 [Computer program]}

The Nordic Cochrane Centre, The Cochrane Collaboration. Review Manager (RevMan). Version 5.1. Copenhagen: The Nordic Cochrane Centre, The Cochrane Collaboration, 2011.

\section{Sandgren 2000}

Sandgren AK, McCaul KD, King B, O'Donnell S, Foreman G. Telephone therapy for patients with breast cancer. Oncology Nursing Forum 2000;27(4):683-8.

\section{Spek 2007}

Spek V, Cuijpers P, Nyklicek I, Riper H, Keyzer J, Pop V. Internet-based cognitive behaviour therapy for symptoms of depression and anxiety: a meta-analysis. Psychological Medicine 2007;37(3):319-28.

\section{Standford 2008}

Standford EA, Chambers CT, Biesanz JC, Chen E. The frequency, trajectories and predictors of adolescent recurrent pain: a population-based approach. Pain 2008;138(1):11-21.

\section{Tuntland 2009}

Tuntland H, Kjeken I, Nordheim LV, Falzon L, Jamtvedt G, Hagen KB. Assistive technology for rheumatoid arthritis Cochrane Database of Systematic Reviews 2009, Issue 4. [DOI: 10.1002/14651858.CD006729.pub2]

\section{Velleman 2010}

Velleman S, Stallard P, Richardson T. A review and meta-analysis of computerized cognitive behaviour therapy for the treatment of pain in children and adolescents. Child: Care, Health and Development 2010;36(4):465-72.

\section{Whitten 2007}

Whitten P, Johannessen LK, Soerensen T, Gammon D, Mackert M. A systematic review of research methodology in telemedicine studies. Journal of Telemedicine and Telecare 2007;13(5):230-5

\section{Williams 2012}

Williams ACDC, Eccleston C, Morley S. Psychological therapies for the management of chronic pain (excluding headache) in adults. Cochrane Database of Systematic Reviews 2012, Issue 11. [DOI: 10.1002/14651858.CD007407.pub3] 
Berman 2009

\begin{tabular}{|c|c|}
\hline Methods & $\mathrm{RCT} ; 2$ arms; assessed pre-treatment and post-treatment (at 6 weeks) \\
\hline \multirow[t]{7}{*}{ Participants } & End of treatment $n=78$ \\
\hline & Start of treatment $n=89$ \\
\hline & Sex $=68 \mathrm{~F}, 10 \mathrm{M}$ \\
\hline & Mean age $=65.8$ years (SD not given) \\
\hline & Source $=$ community-based settings (e.g. community centres) \\
\hline & $\begin{array}{l}\text { Diagnosis = most common causes of pain cited by participants were: arthritis, spinal stenosis or degen- } \\
\text { erative disc problems, previous injuries or surgery, and sciatica. Full descriptions not given }\end{array}$ \\
\hline & Mean years of pain = not given \\
\hline Interventions & $\begin{array}{l}\text { "Online mind-body self care intervention" - "Cognitive-behavioural model with problem solving ap- } \\
\text { proach.... The self-care modules included a selection on mind-body exercises in each of the following } \\
\text { areas: (1) abdominal breathing, (2) relaxation, (3) writing about positive experiences, (4) writing about } \\
\text { difficult experiences, (5) creative visual expression, and (6) positive thinking" }\end{array}$ \\
\hline \multirow[t]{9}{*}{ Outcomes } & Primary pain outcome: Brief Pain Inventory-Short Form (BPI) \\
\hline & Primary disability outcome: none \\
\hline & Primary depression outcome: Centre for Epidemiological Studies Short Depression Scale (CES-D) \\
\hline & Primary anxiety outcome: State-Trait Anxiety Inventory (STAI Y-6) \\
\hline & 1. Pain Self-efficacy Questionnaire \\
\hline & $\begin{array}{l}\text { 2. Awareness of response to pain, using a computed total score for the five relevant items on the Pain } \\
\text { Awareness Questionnaire (PAQ) }\end{array}$ \\
\hline & 3. Confidence with pain management (two items on PAQ) \\
\hline & 4. Satisfaction survey \\
\hline & 5. Self care (one question in the satisfaction survey) \\
\hline
\end{tabular}

Notes

\section{Risk of bias}

\begin{tabular}{lll}
\hline Bias & Authors' judgement & Support for judgement \\
\hline $\begin{array}{l}\text { Random sequence genera- } \\
\text { tion (selection bias) }\end{array}$ & Low risk & $\begin{array}{l}\text { Participants were randomly assigned to either the intervention or comparison } \\
\text { group via a simple coin toss }\end{array}$ \\
\hline $\begin{array}{l}\text { Allocation concealment } \\
\text { (selection bias) }\end{array}$ & High risk & $\begin{array}{l}\text { Group assignment was not concealed, participants assigned to the interven- } \\
\text { tion group received orientation to the website by research assistants }\end{array}$ \\
\hline $\begin{array}{l}\text { Blinding (performance } \\
\text { bias and detection bias) } \\
\text { All outcomes }\end{array}$ & Low risk & Assessments taken online \\
\hline $\begin{array}{l}\text { Incomplete outcome data } \\
\text { (attrition bias) } \\
\text { All outcomes }\end{array}$ & Low risk & $\begin{array}{l}\text { Fewer than 10\% missing data with the exception of CES-D, for which instruc- } \\
\text { tions were followed. Attrition was adequately explained and missing data ap- } \\
\text { peared to have been imputed using appropriate methods }\end{array}$ \\
\hline
\end{tabular}


Berman 2009 (Continued)

Selective reporting (re- Low risk Published report includes data for all expected outcomes porting bias)

Other bias Low risk Study appears to be free of other sources of bias

Bromberg 2011

\begin{tabular}{ll}
\hline Methods & RCT; 2 arms; assessed pretreatment, post-treatment (at 4 weeks) and at follow-up (at 3 and 6 months) \\
\hline Participants & End of treatment $n=144$ \\
& Start of treatment $n=189$ \\
& Sex $=165 \mathrm{~F}, 20 \mathrm{M}$ \\
& Mean age $=42.62$ (SD 11.5) years \\
& Source = recruited through several methods: (1) website postings, (2) electronic newsletter announce- \\
ments, (3) 22 neurology practices that distributed informational flyers to people with chronic pain and \\
(4) postings to social networking/community sites \\
Diagnosis = migraine \\
Mean years of pain = not given \\
$\begin{array}{l}\text { "painACTION, Internet based self-management tool" - "The intervention incorporates cognitive be- } \\
\text { havior therapy and self-management principles to teach people with migraine "how to" apply practical } \\
\text { self-management skills, techniques, and strategies to motivate and support participant engagement in } \\
\text { active pain self-management behaviours. Tasks included completing self assessments, taking lessons } \\
\text { using interactive tools and using a pain tracker" }\end{array}$ \\
\hline Interventions
\end{tabular}

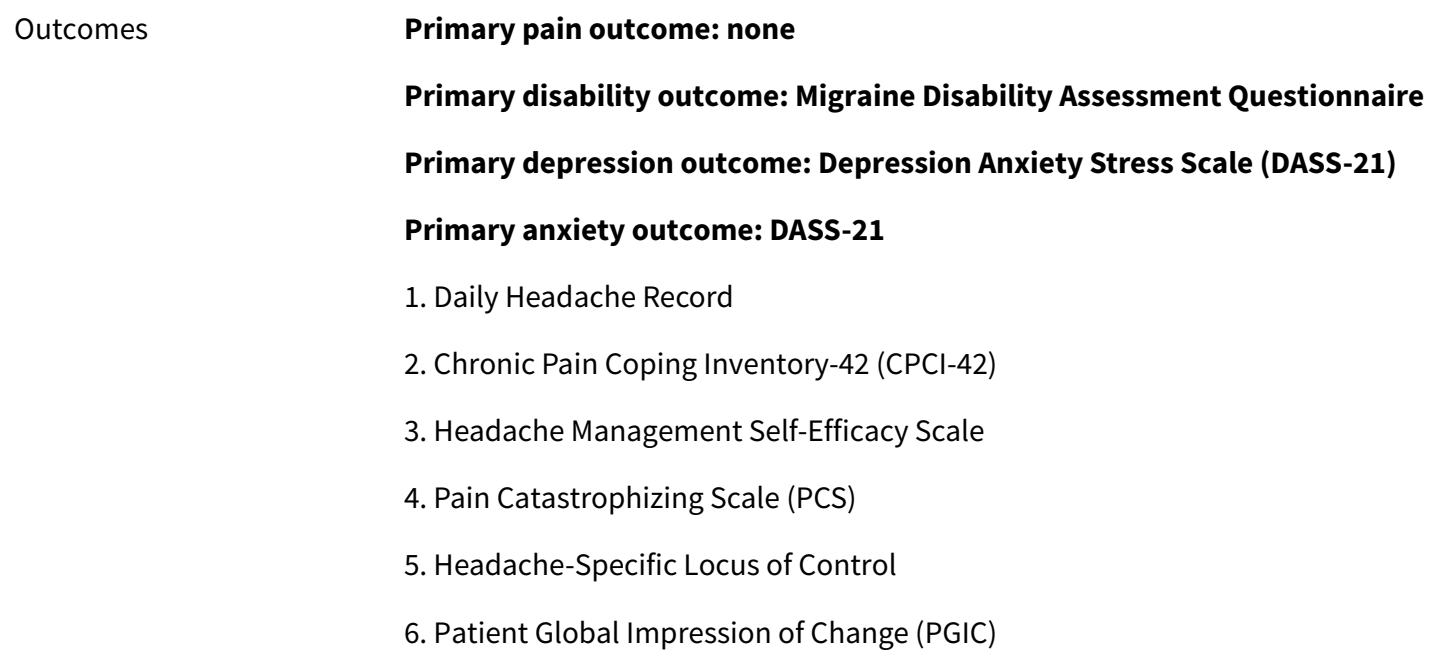

\section{Risk of bias}

\begin{tabular}{lll}
\hline Bias & Authors' judgement & Support for judgement \\
\hline $\begin{array}{l}\text { Random sequence genera- } \\
\text { tion (selection bias) }\end{array}$ & Low risk & Random number table used for group assignment \\
\hline
\end{tabular}


Bromberg 2011 (Continued)

Allocation concealment Unclear risk Study staff created a randomisation table that contained 8 blocks. It is not (selection bias) clear whether study staff were blinded

Blinding (performance Low risk

Assessments taken online

bias and detection bias)

All outcomes

$\begin{array}{lll}\begin{array}{l}\text { Incomplete outcome data } \\ \text { (attrition bias) }\end{array} & \text { High risk } & \begin{array}{l}\text { The study was originally powered for two primary outcomes; however, be- } \\ \text { cause of a data management error one outcome measure was not available for } \\ \text { All outcomes }\end{array} \\ & \begin{array}{l}\text { analysis. Attrition was fully described; however, there were statistical differ- } \\ \text { ences between completers and non-completers }\end{array}\end{array}$

\section{Selective reporting (re- High risk} porting bias)

One expected outcome (Daily Headache Record) was not available due to a data management error, therefore all expected outcomes are not included

Other bias Low risk Study appears to be free of other sources of bias

\section{Buhrman 2004}

\begin{tabular}{|c|c|}
\hline Methods & RCT; 2 arms; assessed pretreatment, post-treatment (at 6 weeks) and at follow-up (at 3 months) \\
\hline \multirow[t]{7}{*}{ Participants } & End of treatment $n=51$ \\
\hline & Start of treatment $n=51$ \\
\hline & Sex $=21 \mathrm{~F}, 35 \mathrm{M}$ \\
\hline & Mean age $=44.6($ SD 10.4) years \\
\hline & Source $=$ newspaper articles in national and regional papers as well as through a webpage for health \\
\hline & Diagnosis = chronic back pain \\
\hline & Mean years of pain $=10.1($ SD 9.2) years \\
\hline Interventions & $\begin{array}{l}\text { "Internet based pain management programme with telephone support" - "Treatment model delivered } \\
\text { was derived primarily from a cognitive-behavioural model of chronic pain... and included psychologi- } \\
\text { cal components (e.g. dealing with unhelpful thoughts and beliefs, changing focus) as well as stretching } \\
\text { and physical exercises.... Telephone contact was with a therapist once a week to review homework, an- } \\
\text { swer questions and maintain motivation" }\end{array}$ \\
\hline \multirow[t]{9}{*}{ Outcomes } & Primary pain outcome: Multidimensional Pain Inventory (MPI) \\
\hline & Primary disability outcome: none \\
\hline & Primary depression outcome: Hospital Anxiety and Depression Scale (HADS) \\
\hline & Primary anxiety outcome: HADS \\
\hline & 1. Coping Strategies Questionnaire \\
\hline & 2. Pain and Impairment Relationship Scale (PAIRS) \\
\hline & 3. Pain Diary \\
\hline & 4. Treatment credibility - 5 items on an adapted 10-point scale \\
\hline & 5. Satisfaction with treatment format \\
\hline
\end{tabular}


Buhrman 2004 (Continued)

Notes

\section{Risk of bias}

\begin{tabular}{|c|c|c|}
\hline Bias & Authors' judgement & Support for judgement \\
\hline $\begin{array}{l}\text { Random sequence genera- } \\
\text { tion (selection bias) }\end{array}$ & Low risk & $\begin{array}{l}\text { Subjects were randomised using dice, where even numbers meant treatment } \\
\text { and odd numbers meant control condition }\end{array}$ \\
\hline $\begin{array}{l}\text { Allocation concealment } \\
\text { (selection bias) }\end{array}$ & Unclear risk & Insufficient information regarding allocation concealment \\
\hline $\begin{array}{l}\text { Blinding (performance } \\
\text { bias and detection bias) } \\
\text { All outcomes }\end{array}$ & Low risk & Assessments taken online \\
\hline $\begin{array}{l}\text { Incomplete outcome data } \\
\text { (attrition bias) } \\
\text { All outcomes }\end{array}$ & Low risk & $\begin{array}{l}\text { Report } \mathrm{n}=5 \text { dropped out, reason for attrition is not documented. Differences } \\
\text { between completers and non-completers reported }\end{array}$ \\
\hline $\begin{array}{l}\text { Selective reporting (re- } \\
\text { porting bias) }\end{array}$ & Low risk & Published report includes data for all expected outcomes \\
\hline Other bias & Low risk & Study appears to be free of other sources of bias \\
\hline
\end{tabular}

Buhrman 2011

\begin{tabular}{ll}
\hline Methods & RCT; 2 arms; assessed pretreatment, post-treatment (at 12 weeks) \\
\hline Participants & End of treatment $n=50$ \\
Start of treatment $n=54$ \\
Sex $=37 \mathrm{~F}, 17 \mathrm{M}$ \\
Mean age $=43.2$ (SD 9.8) years \\
Source = newspaper articles in national and regional papers, as well as recruitment through a webpage \\
Diagnosis = chronic back pain \\
Mean years of pain = 12.1 (SD 8.5) years
\end{tabular}

Interventions "Guided Internet-based cognitive behavioural treatment" - "Self help management programme administered via the Internet... based on CBT. The participants were instructed to test and practice different coping strategies e.g. relaxation, cognitive skills, stress management as well as physical exercise techniques... The text was divided into 8 modules. Participants were prompted to submit weekly reports on treatment progress. Treatment group had one structured telephone conversation with a therapist and access to a computer technician via email."

\section{Outcomes}

\section{Primary pain outcome: MPI \\ Primary disability outcome: none \\ Primary depression outcome: HADS \\ Primary anxiety outcome: HADS}


Buhrman 2011 (Continued)
1. Coping Strategies Questionnaire
2. PAIRS
3. Quality of life inventory

\section{Notes}

\section{Risk of bias}

\begin{tabular}{lll}
\hline Bias & Authors' judgement & Support for judgement \\
\hline $\begin{array}{l}\text { Random sequence genera- } \\
\text { tion (selection bias) }\end{array}$ & Unclear risk & $\begin{array}{l}\text { Randomisation was made by an independent person through a webpage with } \\
\text { a randomisation program. Method used unclear }\end{array}$ \\
\hline $\begin{array}{l}\text { Allocation concealment } \\
\text { (selection bias) }\end{array}$ & Low risk & $\begin{array}{l}\text { Randomisation was made by an independent person through a webpage with } \\
\text { a randomisation program. Third-party involvement therefore meets the crite- } \\
\text { ria for concealment }\end{array}$ \\
\hline $\begin{array}{l}\text { Blinding (performance } \\
\text { bias and detection bias) }\end{array}$ & Low risk & $\begin{array}{l}\text { Assessments taken online } \\
\text { All outcomes }\end{array}$ \\
\hline $\begin{array}{l}\text { Incomplete outcome data } \\
\text { (attrition bias) } \\
\text { All outcomes }\end{array}$ & Low risk & $\begin{array}{l}\text { "Data were analysed using the intention-to-treat principle with all available } \\
\text { data regardless of completion of the actual treatment. Participants lost to fol- } \\
\text { low-up were first not replaced using last observation carried forward, as this } \\
\text { assumes stability from pre-treatment. Given the few drop-outs, the authors re- } \\
\text { garded this as a defensible procedure instead of modelling the lost observa- } \\
\text { tions ( } n=5) \text { using bootstrap methodology or mixed models approaches. All } \\
\text { analyses were repeated with the } 5 \text { missing cases replaced by their baseline da- } \\
\text { ta. This did not affect the outcome" }\end{array}$ \\
\hline
\end{tabular}
Selective reporting (re-
Low risk
Published report includes data for all expected outcomes porting bias)

Other bias Low risk Study appears to be free of other sources of bias

Buhrman 2013

\begin{tabular}{ll}
\hline Methods & RCT; 2 arms; assessed pretreatment, post-treatment, and at 6 months. \\
\hline Participants & End of treatment $n=56$ \\
& Start of treatment $n=72$ \\
& Sex $=52 \mathrm{~F}, 20 \mathrm{M}$ \\
& Mean age $=40.1$ (SD 8.94) years \\
& Source $=$ former attendants at a pain centre \\
& Diagnosis = back, neck, shoulder, and generalised pain \\
& Mean years of pain = 6.2 (SD 2.07) years \\
Interventions & $\begin{array}{l}\text { Eight treatment modules of the Internet programme, CBT-based. Included relaxation, physical exercise } \\
\text { plan, balance when planning activities, cognitive restructuring, mindfulness, stress management, sleep } \\
\text { hygiene }\end{array}$
\end{tabular}




Primary pain outcome: MPI
Primary disability outcome: none
Primary depression outcome: HADS
Primary anxiety outcome: HADS
1. Coping Strategies Questionnaire
2. PAIRS
3. Quality of life inventory
4. Chronic Pain Acceptance Questionnaire

Notes

Risk of bias

\begin{tabular}{|c|c|c|}
\hline Bias & Authors' judgement & Support for judgement \\
\hline $\begin{array}{l}\text { Random sequence genera- } \\
\text { tion (selection bias) }\end{array}$ & Low risk & $\begin{array}{l}\text { "Randomization was made by an independent person using a true random } \\
\text { number service" }\end{array}$ \\
\hline $\begin{array}{l}\text { Allocation concealment } \\
\text { (selection bias) }\end{array}$ & Low risk & $\begin{array}{l}\text { "Randomization was made by an independent person using a true random } \\
\text { number service" }\end{array}$ \\
\hline $\begin{array}{l}\text { Blinding (performance } \\
\text { bias and detection bias) } \\
\text { All outcomes }\end{array}$ & Low risk & Assessments taken online \\
\hline $\begin{array}{l}\text { Incomplete outcome data } \\
\text { (attrition bias) } \\
\text { All outcomes }\end{array}$ & Low risk & $\begin{array}{l}\text { Attrition fully reported, no statistical differences between completers and non- } \\
\text { completers }\end{array}$ \\
\hline $\begin{array}{l}\text { Selective reporting (re- } \\
\text { porting bias) }\end{array}$ & Low risk & Published report includes data for all expected outcomes \\
\hline Other bias & Low risk & Study appears to be free of other sources of bias \\
\hline
\end{tabular}

Buhrman 2013a

\begin{tabular}{ll}
\hline Methods & RCT; 2 arms; assessed pretreatment, post-treatment, and at 6 months. \\
\hline Participants & End of treatment $n=61$ \\
Start of treatment $n=76$ \\
Sex $=45 \mathrm{~F}, 31 \mathrm{M}$ \\
Mean age $=49.1$ (SD 10.34) years \\
Source = attendants at a pain centre \\
Diagnosis = back, neck, shoulder, hips/legs/feet, and generalised pain
\end{tabular}


Buhrman 2013a (Continued)

Mean years of pain $=15.3($ SD 11.65) years

Interventions Seven treatment sections ACT-based. MP3 files could be played on MP3 player or computer. Treatment involved learning and practising mindfulness exercises

Control group participated in an online discussion forum with weekly discussion topics presented

Primary pain outcome: MPI
Primary disability outcome: none
Primary depression outcome: HADS
Primary anxiety outcome: HADS
1. Coping Strategies Questionnaire
2. PAIRS
3. Quality of life inventory
4. Chronic Pain Acceptance Questionnaire

Notes

\section{Risk of bias}

\begin{tabular}{lll}
\hline Bias & Authors' judgement & Support for judgement \\
\hline $\begin{array}{l}\text { Random sequence genera- } \\
\text { tion (selection bias) }\end{array}$ & Low risk & $\begin{array}{l}\text { "76 patients remained and were randomized to either the treatment or to the } \\
\text { control group.... Using a true random number service" }\end{array}$ \\
\hline $\begin{array}{l}\text { Allocation concealment } \\
\text { (selection bias) }\end{array}$ & Low risk & $\begin{array}{l}\text { "Randomization was made by an independent person using a true random } \\
\text { number service" }\end{array}$ \\
\hline $\begin{array}{l}\text { Blinding (performance } \\
\text { bias and detection bias) } \\
\text { All outcomes }\end{array}$ & Low risk & Assessments taken online \\
\hline $\begin{array}{l}\text { Incomplete outcome data } \\
\text { (attrition bias) } \\
\text { All outcomes }\end{array}$ & Unclear risk & $\begin{array}{l}\text { Attrition reported in flow diagram. Differences between dropouts and com- } \\
\text { pleters not reported. Intension-to-treat analyses carried out. }\end{array}$ \\
\hline $\begin{array}{l}\text { Selective reporting (re- } \\
\text { porting bias) }\end{array}$ & Low risk & Published report includes data for all expected outcomes \\
\hline \begin{tabular}{l} 
Other bias \\
\hline
\end{tabular} & Low risk & Study appears to be free of other sources of bias \\
\hline
\end{tabular}

\section{Carpenter 2012}

\begin{tabular}{ll}
\hline Methods & RCT; 2 arms; assessed pretreatment, post-treatment (at 3 weeks) and at follow-up (at 6 weeks) \\
\hline Participants & End of treatment $n=131$ \\
& Start of treatment $n=141$ \\
& Sex $=117 \mathrm{~F}, 24 \mathrm{M}$ \\
Mean age $=42.5$ (SD 10.3) years
\end{tabular}


Carpenter 2012 (Continued)

Source $=$ Internet bulletin boards and advertisements in mainstream and alternative newspapers

Diagnosis = chronic lower back pain

Mean years of pain $=8.6(S D 7.8)$ years

Interventions

"Online self-help intervention (Wellness Workbook)" - online interactive CBT intervention. It uses a mind/body treatment rational, including content on: pain education, CBT techniques (including cognitive restructuring), stress management, relaxation, mindfulness and values-based behavioural activation.

Primary pain outcome: Pain Assessment Questionnaire (pain rating of average pain)
Primary disability outcome: Roland-Morris Disability
Primary depression outcome: none
Primary anxiety outcome: PCS
1. Survey of Pain Attitudes
2. Arthritis Self Efficacy Scale
3. The Fear Avoidance Beliefs Questionnaire (FABQ)
4. The Negative Mood Regulation Scale
5. Demographics and Pain Assessment Questionnaire

\section{Risk of bias}

\begin{tabular}{lll}
\hline Bias & Authors' judgement & Support for judgement \\
\hline $\begin{array}{l}\text { Random sequence genera- } \\
\text { tion (selection bias) }\end{array}$ & Low risk & Randomised using a random number table \\
\hline $\begin{array}{l}\text { Allocation concealment } \\
\text { (selection bias) }\end{array}$ & Unclear risk & Insufficient information regarding allocation concealment \\
\hline $\begin{array}{l}\text { Blinding (performance } \\
\text { bias and detection bias) } \\
\text { All outcomes }\end{array}$ & Low risk & Assessments taken online \\
\hline $\begin{array}{l}\text { Incomplete outcome data } \\
\text { (attrition bias) }\end{array}$ & Unclear risk & $\begin{array}{l}\text { There was differential attrition between the two groups with higher dropout in } \\
\text { the wait-list condition. Compared with completers, non-completers were sig- } \\
\text { nificantly more likely to be men, older in age and have lower average pain }\end{array}$ \\
\hline $\begin{array}{l}\text { Selective reporting (re- } \\
\text { porting bias) }\end{array}$ & High risk & $\begin{array}{l}\text { Pain ratings not described as an outcome measure in the methods, and not re- } \\
\text { ported at 6-week follow-up. The report includes all data for the other expected } \\
\text { outcomes }\end{array}$ \\
\hline \begin{tabular}{l} 
Other bias \\
\hline
\end{tabular} & Low risk & \begin{tabular}{l} 
Study appears to be free of other sources of bias \\
\hline
\end{tabular}
\end{tabular}

Chiauzzi 2010

Methods $\quad$ RCT; 2 arms; assessed pretreatment, post-treatment (at 4 weeks) and at follow-up (at 3 and 6 months)


Chiauzzi 2010 (Continued)

\begin{tabular}{|c|c|}
\hline Participants & End of treatment $n=186$ \\
\hline & Start of treatment $n=209$ \\
\hline & Sex $=134 \mathrm{~F}, 64 \mathrm{M}$ \\
\hline & Mean age $=46.14$ (SD 11.99) years \\
\hline & $\begin{array}{l}\text { Source = "online dissemination through professional and patient } \mathrm{c} \\
\text { centre" }\end{array}$ \\
\hline & Diagnosis = chronic back pain \\
\hline & Mean years of pain $=$ not given \\
\hline Interventions & $\begin{array}{l}\text { "painACTION, Internet based self-management tool" - painACTION } \\
\text { CBT and self-management principles. The intervention includes co } \\
\text { cision making with health professionals; 2) CBT to improve self-effi } \\
\text { set clinical goals, work on problem-solving life situations, and prev } \\
\text { enhancement through tailored feedback; and (4) wellness activitie } \\
\text { stress management, and exercise practices. }\end{array}$ \\
\hline Outcomes & Primary pain outcome: BPI \\
\hline & Primary disability outcome: Oswestry Disability Questionnaire \\
\hline & Primary depression outcome: DASS-21 \\
\hline & Primary anxiety outcome: DASS-21 \\
\hline & 1. PGIC \\
\hline & 2. $\mathrm{CPCl}-42$ \\
\hline & 3. PCS \\
\hline & 4. Pain Self-Efficacy Questionnaire \\
\hline & 5. FABQ \\
\hline
\end{tabular}

\section{Notes}

\section{Risk of bias}

\begin{tabular}{lll}
\hline Bias & Authors' judgement & Support for judgement \\
\hline $\begin{array}{l}\text { Random sequence genera- } \\
\text { tion (selection bias) }\end{array}$ & Unclear risk & $\begin{array}{l}\text { Participants were randomised using an adaptive or "stratified" randomisation } \\
\text { that ensures group equivalence on preselected variables that may relate to } \\
\text { outcome across conditions. Gender, race/ethnicity, and age bracket (18 to } 40, \\
41 \text { to } 60,60 \text { years and over) were included in the randomisation algorithm. No } \\
\text { method described }\end{array}$ \\
\hline $\begin{array}{ll}\text { Allocation concealment } \\
\text { (selection bias) }\end{array}$ & Unclear risk & Insufficient information regarding allocation concealment \\
\hline $\begin{array}{l}\text { Blinding (performance } \\
\text { bias and detection bias) }\end{array}$ & Unclear risk & No description given \\
All outcomes & \\
\hline
\end{tabular}

$\begin{array}{lll}\begin{array}{l}\text { Incomplete outcome data } \\ \text { (attrition bias) }\end{array} & \text { Unclear risk } & \begin{array}{l}\text { Attrition reported. Differences between completers and non-completers not } \\ \text { reported }\end{array}\end{array}$


Chiauzzi 2010 (Continued)

All outcomes

Selective reporting (re- Low risk $\quad$ The report includes all data for expected outcomes
porting bias)

Other bias Low risk Study appears to be free of other sources of bias

Dear 2013

\begin{tabular}{|c|c|}
\hline Methods & $\mathrm{RCT} ; 2$ arms; assessed pretreatment, post-treatment and at 3 months \\
\hline \multirow[t]{7}{*}{ Participants } & End of treatment $n=62$ \\
\hline & Start of treatment $n=60$ \\
\hline & Sex $=27 \mathrm{~F}, 4 \mathrm{M}$ \\
\hline & Mean age $=47(\mathrm{SD} 13)$ years \\
\hline & $\begin{array}{l}\text { Source = advertisements about the trial were placed in newsletters and on websites operated by non- } \\
\text { governmental institutions that offer information and services to people with chronic pain, including } \\
\text { beyondblue, Chronic Pain Australia, Australian Pain Management Association, and Arthritis Australia. }\end{array}$ \\
\hline & Diagnosis $=$ mixed body pain sites \\
\hline & Mean years of pain $=7.36($ SD 8.10$)$ years \\
\hline Interventions & $\begin{array}{l}\text { "The Pain Course" based on principles of CBT. Modules include sleep hygiene, problem-solving, as- } \\
\text { sertiveness, managing attention, and core beliefs. } 8 \text { weeks in length. Wait-list control }\end{array}$ \\
\hline \multirow[t]{7}{*}{ Outcomes } & Primary pain outcome: Wisconsin Brief Pain Questionnaire \\
\hline & Primary disability outcome: Roland-Morris Disability Questionnaire \\
\hline & Primary depression outcome: Patient Health Questionnaire 9-Item \\
\hline & Primary anxiety outcome: Generalized Anxiety Disorder 7-Item \\
\hline & 1. Pain Self-efficacy questionnaire \\
\hline & 2. TAMPA Scale of Kinesiophobia \\
\hline & 3. Pain Responses Self-Statements \\
\hline
\end{tabular}

Notes

Risk of bias

\begin{tabular}{lll}
\hline Bias & Authors' judgement & Support for judgement \\
\hline $\begin{array}{l}\text { Random sequence genera- } \\
\text { tion (selection bias) }\end{array}$ & High risk & No method described \\
\hline $\begin{array}{l}\text { Allocation concealment } \\
\text { (selection bias) }\end{array}$ & High risk & No method described \\
\hline $\begin{array}{l}\text { Blinding (performance } \\
\text { bias and detection bias) } \\
\text { All outcomes }\end{array}$ & Low risk & Assessments taken online \\
\hline \hline
\end{tabular}

Psychological therapies (Internet-delivered) for the management of chronic pain in adults (Review) 
Dear 2013 (Continued)

\begin{tabular}{|c|c|c|}
\hline $\begin{array}{l}\text { Incomplete outcome data } \\
\text { (attrition bias) }\end{array}$ & Unclear risk & $\begin{array}{l}\text { Attrition reported, differences between completers and non-completers not } \\
\text { described }\end{array}$ \\
\hline
\end{tabular}

All outcomes described

\begin{tabular}{lll}
\hline $\begin{array}{l}\text { Selective reporting (re- } \\
\text { porting bias) }\end{array}$ & Low risk & The report includes all data for expected outcomes \\
\hline Other bias & Low risk & Study appears to be free of other sources of bias \\
\hline
\end{tabular}

Devineni 2005

\begin{tabular}{ll}
\hline Methods & RCT; 2 arms; assessed pretreatment, post-treatment (at 4 weeks) and at follow-up (at 2 months) \\
\hline Participants & End of treatment $n=86$ \\
Start of treatment $n=86$ & Sex $=108 \mathrm{~F}, 31 \mathrm{M}$ \\
& Mean age $=42.3$ (SD 11.9) years \\
& Source = common Internet-based promotion channels \\
& Diagnosis = chronic headache \\
& Mean years of pain = not given \\
& "Internet-delivered behavioural regimen" - Behavioural regimen composed of: progressive muscle re- \\
laxation, limited biofeedback with autogenic training and stress management.
\end{tabular}

$\begin{array}{ll}\text { Outcomes } & \text { Primary pain outcome: Headache Symptom Questionnaire } \\ \text { Primary disability outcome: Headache Disability Inventory (HDI) } \\ \text { Primary depression outcome: CES-D } \\ \text { Primary anxiety outcome: STAI }\end{array}$

Primary anxiety outcome: STAI

Notes

\begin{tabular}{|c|c|c|}
\hline \multicolumn{3}{|l|}{ Risk of bias } \\
\hline Bias & Authors' judgement & Support for judgement \\
\hline $\begin{array}{l}\text { Random sequence genera- } \\
\text { tion (selection bias) }\end{array}$ & Unclear risk & $\begin{array}{l}\text { Reports that participants were randomly assigned to either immediate treat- } \\
\text { ment or symptom monitoring control; however, randomisation method is not } \\
\text { specified }\end{array}$ \\
\hline $\begin{array}{l}\text { Allocation concealment } \\
\text { (selection bias) }\end{array}$ & Unclear risk & Insufficient information regarding allocation concealment \\
\hline $\begin{array}{l}\text { Blinding (performance } \\
\text { bias and detection bias) } \\
\text { All outcomes }\end{array}$ & Low risk & Assessments taken online \\
\hline $\begin{array}{l}\text { Incomplete outcome data } \\
\text { (attrition bias) }\end{array}$ & Low risk & $\begin{array}{l}\text { Subject flow through phases of the project is detailed along with dropout pre- } \\
\text { dictors. Although attrition rate is high, this is acknowledged and discussed }\end{array}$ \\
\hline
\end{tabular}


Devineni 2005 (Continued)

All outcomes

Selective reporting (reporting bias)
High risk

Follow-up data is not fully reported. Post-treatment data are fully reported

Other bias Low risk Study appears to be free of other sources of bias

\section{Hedborg 2011}

\begin{tabular}{|c|c|}
\hline Methods & RCT; 3 arms; pretreatment, 8 months (experimental and control), 11 months (experimental only) \\
\hline \multirow[t]{7}{*}{ Participants } & End of treatment $n=76$ \\
\hline & Start of treatment $n=83$ \\
\hline & Sex $=58 \mathrm{~F}, 25 \mathrm{M}$ \\
\hline & Mean age $=47.73$ (SD not given) years \\
\hline & $\begin{array}{l}\text { Source = participants were recruited after being approached during a previous descriptive study on mi- } \\
\text { graine }\end{array}$ \\
\hline & Diagnosis = migraine \\
\hline & Mean years of pain $=23.2$ years (SD not given) \\
\hline Interventions & $\begin{array}{l}\text { "Internet-based multimodal behavior treatment (MBT) with hand massage" - "The MBT program was } \\
\text { intended to increase participants' awareness of essential factors in everyday life that might have an im- } \\
\text { pact on their migraine. This training program consisted of the following topics: stress physiology, phys- } \\
\text { ical activity, diet, thought patterns, handling of emotions, and attitudes (toward oneself and others)" }\end{array}$ \\
\hline
\end{tabular}

\section{Outcomes}

\section{Primary pain outcome: none}

Primary disability outcome: none

Primary depression outcome: Montgomery-Asberg Depression Rating Scale

\section{Primary anxiety outcome: none}

1) PQS23 - An instrument developed at the Department of Environmental Stress Disorders (CEOS), Uppsala University

2) Assessment of opinions about MBT and hand massage interventions

$\begin{array}{ll}\text { Notes } & \begin{array}{l}\text { Outcome measures at } 8 \text { months are used as there are no post-treatment measures for the control } \\ \text { group }\end{array}\end{array}$

\section{Risk of bias}

\begin{tabular}{lll}
\hline Bias & Authors' judgement & Support for judgement \\
\hline $\begin{array}{ll}\text { Random sequence genera- } \\
\text { tion (selection bias) }\end{array}$ & Low risk & $\begin{array}{l}\text { "A sequence of random numbers was generated in Statistical Package for the } \\
\text { Social Sciences } 18.0 \text { (SPSS) software, stratified by gender in order to obtain } \\
\text { an equal distribution of women and men in the groups. Based on magnitude, } \\
\text { these numbers were arranged into three equal-sized groups, which translat- } \\
\text { ed into the three study groups. The number sequence thus translated into a } \\
\text { unique sequence of group affiliation which corresponded to the chronological } \\
\text { order of inclusion" }\end{array}$
\end{tabular}


Hedborg 2011 (Continued)

Allocation concealment Low risk The randomisation procedure was performed by an independent researcher, (selection bias) thus the process was blinded to the investigators

Blinding (performance Low risk

bias and detection bias)

All outcomes
Assessments taken online

Incomplete outcome data Low risk

(attrition bias)

Attrition fully reported, no statistical differences between completers and non-

All outcomes completers

Selective reporting (re- Low risk Reported all data for expected outcomes
porting bias)

Other bias Low risk Study appears to be free of other sources of bias

Lorig 2008

\begin{tabular}{|c|c|}
\hline Methods & RCT; 2 arms; assessed pretreatment, post-treatment (at 6 months) and at follow-up (at 12 months) \\
\hline Participants & $\begin{array}{l}\text { End of treatment } n=641 \\
\text { Start of treatment } n=855 \\
\text { Sex }=781 \mathrm{~F}, 74 \mathrm{M} \\
\text { Mean age = } 52.35 \text { (SD 11.55) years } \\
\text { Source = established websites, online newsletters and discussion groups } \\
\text { Diagnosis = rheumatoid arthritis, osteoarthritis or fibromyalgia } \\
\text { Mean years of pain = not given }\end{array}$ \\
\hline Interventions & $\begin{array}{l}\text { "Internet-based Arthritis Self-Management Program (ASMP)" - "ASMP consists of password protected, } \\
\text { interactive, Web-based instruction (The Learning Center); Web-based bulletin board discussion (The } \\
\text { Discussion Center); tools that the participants can use individually, such as exercise logs, medication } \\
\text { diaries, and tailored exercise programmes. The Learning Center content includes design of individual- } \\
\text { ized exercise programmes; use of cognitive symptom management such as relaxation, visualization, } \\
\text { distraction, and self-talk; methods for managing negative emotions such as anger, fear, and depres- } \\
\text { sion; an overview of medications; aspects of physician-patient communication; healthy eating; fatigue } \\
\text { management; action planning; feedback; and methods for solving arthritis related problems" }\end{array}$ \\
\hline
\end{tabular}

Outcomes

Primary pain outcome: Health indicator - Pain (0-10)

Primary disability outcome: Health indicator - Disability (0-3)

Primary depression outcome: none

Primary anxiety outcome: none

1. Six health-related quality of life indicators (Health distress, Self reported global health, Disability, Activity limitation, Fatigue, Pain)

2. Four health-related behaviours (stretching and strengthening exercises, aerobic exercise, use of cognitive symptom techniques and use of techniques to improve communication with healthcare providers) 
Lorig 2008 (Continued)

3. Five utilisation measures (self-reported outpatient visits to physicians, emergency room visits, nights in the hospital, chiropractic visits and physical therapy visits)

4. Arthritis Self-Efficacy Scale

Notes

Intervention duration was 6 weeks, post-treatment outcome measures assessed at 6 months

\section{Risk of bias}

\begin{tabular}{|c|c|c|}
\hline Bias & Authors' judgement & Support for judgement \\
\hline $\begin{array}{l}\text { Random sequence genera- } \\
\text { tion (selection bias) }\end{array}$ & Unclear risk & $\begin{array}{l}\text { Reports that participants were randomised to either the intervention group or } \\
\text { to a control group; however, does not give any information about randomisa- } \\
\text { tion method }\end{array}$ \\
\hline $\begin{array}{l}\text { Allocation concealment } \\
\text { (selection bias) }\end{array}$ & Unclear risk & Insufficient information regarding allocation concealment \\
\hline $\begin{array}{l}\text { Blinding (performance } \\
\text { bias and detection bias) } \\
\text { All outcomes }\end{array}$ & Low risk & Assessments taken online \\
\hline $\begin{array}{l}\text { Incomplete outcome data } \\
\text { (attrition bias) } \\
\text { All outcomes }\end{array}$ & High risk & $\begin{array}{l}\text { Attrition fully reported, statistical differences between completers and non- } \\
\text { completers }\end{array}$ \\
\hline $\begin{array}{l}\text { Selective reporting (re- } \\
\text { porting bias) }\end{array}$ & Low risk & Published report includes data for all expected outcomes \\
\hline Other bias & Low risk & Study appears to be free of other sources of bias \\
\hline
\end{tabular}

\section{Ruehlman 2012}

\begin{tabular}{|c|c|}
\hline Methods & RCT; 2 arms; assessed pretreatment, post-treatment (at 7 weeks) and at follow-up (at 14 weeks) \\
\hline \multirow[t]{7}{*}{ Participants } & End of treatment $n=241$ \\
\hline & Start of treatment $n=305$ \\
\hline & Sex $=195 \mathrm{~F}, 110 \mathrm{M}$ \\
\hline & Mean age $=$ not given \\
\hline & Source $=$ established websites, e-mails to website members and newsletters \\
\hline & $\begin{array}{l}\text { Diagnosis = "The most common diagnoses were migraine headaches }(65.5 \%) \text { and back injury }(60.5 \%) \text {. } \\
\text { Tension headaches, fibromyalgia, osteoarthritis, face or jaw pain, and premenstrual pain were some- } \\
\text { what less common, with } 20-40 \% \text { of the participants reporting these". }\end{array}$ \\
\hline & $\begin{array}{l}\text { Mean years of pain = Not given; however, } 89.5 \% \text { of participants reported having pain for more than } 2 \\
\text { years }\end{array}$ \\
\hline Interventions & $\begin{array}{l}\text { "The Chronic Pain Management Program (CPMP)" - "CPMP leverages technical capabilities with pro- } \\
\text { gram content and functionality derived from cognitive behavior therapy, interpersonal, and self-man- } \\
\text { agement approaches to address the adaptive burdens of chronic pain in adults. A custom learning plan } \\
\text { is created for each user after the online completion of the Profile of Chronic Pain (PCP). The PCP in- } \\
\text { cludes online activities (e.g. interactive exercises) and off-line activities (e.g. lifestyle activities such as } \\
\text { exercise)" }\end{array}$ \\
\hline
\end{tabular}


Ruehlman 2012 (Continued)

Outcomes
Primary pain outcome: Profile of Chronic Pain (PCP): Screen

Primary disability outcome: none

Primary depression outcome: CES-D

Primary anxiety outcome: DASS-21

1. Test of pain knowledge that assessed the role of thought, emotion, social responses to pain and behaviour to the pain experience

2. PCP: Extended Assessment

3. Functional limitations in 10 areas of daily living (social life, sex, sleep, recreation, chores, work, selfcare, parenting, routine physical activities and exercise)

\section{Notes}

\section{Risk of bias}

\begin{tabular}{|c|c|c|}
\hline Bias & Authors' judgement & Support for judgement \\
\hline $\begin{array}{l}\text { Random sequence genera- } \\
\text { tion (selection bias) }\end{array}$ & Unclear risk & $\begin{array}{l}\text { Reports participants were randomised; however, randomisation method is not } \\
\text { specified }\end{array}$ \\
\hline $\begin{array}{l}\text { Allocation concealment } \\
\text { (selection bias) }\end{array}$ & Unclear risk & Insufficient information regarding allocation concealment \\
\hline $\begin{array}{l}\text { Blinding (performance } \\
\text { bias and detection bias) } \\
\text { All outcomes }\end{array}$ & Low risk & Assessments taken online \\
\hline $\begin{array}{l}\text { Incomplete outcome data } \\
\text { (attrition bias) } \\
\text { All outcomes }\end{array}$ & Low risk & $\begin{array}{l}\text { Chi } 2 \text { tests indicated that the probability of missing data differed across the } 2 \\
\text { conditions, with the experimental group having the higher missing data rate. } \\
\text { Authors used full information maximum likelihood estimation to deal with } \\
\text { missing data }\end{array}$ \\
\hline $\begin{array}{l}\text { Selective reporting (re- } \\
\text { porting bias) }\end{array}$ & Low risk & Published report includes data for all expected outcomes \\
\hline Other bias & Low risk & Study appears to be free of other sources of bias \\
\hline
\end{tabular}

Strom 2000

\begin{tabular}{ll}
\hline Methods & RCT; 2 arms; assessed pretreatment and post-treatment (at 6 weeks) \\
\hline Participants & End of treatment $n=45$ \\
& Start of treatment $n=45$ \\
& Sex $=69 \mathrm{~F}, 33 \mathrm{M}$ \\
& Mean age $=36.7$ years (SD not given) \\
& Source = participants were recruited by means of newspaper articles in national and regional papers \\
and notes in Internet magazines & Diagnosis = recurrent headache
\end{tabular}


Strom 2000 (Continued)

$$
\text { Mean years of pain = not given }
$$

Interventions

"Self help treatment, applied relaxation and problem solving" - "The relaxation program was largely derived from the method of applied relaxation... and autogenic training.... The instructions were adjusted to suit the self help format. Participants were presented with different methods aimed to be useful in the identification of problems, coping with problems in general, and coping with headache-related problems..."
Primary pain outcome: Headache Index

Primary disability outcome: HDI

Primary depression outcome: BDI

Primary anxiety outcome: none

1. Number of headache days per week

2. Peak intensity of headache

3. Multidimensional Locus of Pain Control Questionnaire (MLPC)

\section{Notes}

\section{Risk of bias}

\begin{tabular}{|c|c|c|}
\hline Bias & Authors' judgement & Support for judgement \\
\hline $\begin{array}{l}\text { Random sequence genera- } \\
\text { tion (selection bias) }\end{array}$ & Unclear risk & $\begin{array}{l}\text { Report that participants were randomised into either treatment or waiting-list } \\
\text { condition; however, randomisation method is not specified }\end{array}$ \\
\hline $\begin{array}{l}\text { Allocation concealment } \\
\text { (selection bias) }\end{array}$ & Unclear risk & Insufficient information regarding allocation concealment \\
\hline $\begin{array}{l}\text { Blinding (performance } \\
\text { bias and detection bias) } \\
\text { All outcomes }\end{array}$ & Unclear risk & $\begin{array}{l}\text { Some questionnaires taken online, other questionnaires filled out on paper. } \\
\text { No description given if outcome assessors were blinded }\end{array}$ \\
\hline $\begin{array}{l}\text { Incomplete outcome data } \\
\text { (attrition bias) } \\
\text { All outcomes }\end{array}$ & Unclear risk & $\begin{array}{l}\text { Acknowledges that the dropout rate was proportionately large }(56 \%) \text {; howev- } \\
\text { er, there is insufficient reporting of attrition reasons. Dropouts tended to be } \\
\text { younger and had a headache for a shorter duration }\end{array}$ \\
\hline $\begin{array}{l}\text { Selective reporting (re- } \\
\text { porting bias) }\end{array}$ & High risk & Results of the MLPC questionnaire are not reported \\
\hline Other bias & Low risk & Study appears to be free of other sources of bias \\
\hline
\end{tabular}

Williams 2010

\begin{tabular}{ll}
\hline Methods & RCT; 2 arms; assessed pretreatment and post-treatment (at 6 months) \\
\hline Participants & End of treatment $n=106$ \\
& Start of treatment $n=118$ \\
& Sex $=112$ F, $6 \mathrm{M}$ \\
& Mean age $=50.46$ (SD 11.45) years
\end{tabular}


Williams 2010 (Continued)

Source = conducted at the Avera Research Institute; participants were referred to the study by their primary or specialist care physician, who received recruitment materials through their local provider network

Diagnosis $=$ fibromyalgia

Mean years of pain $=9.4($ SD 6.46) years

Interventions
"Internet based exercise and behavioural self-management" - "The website entitled "Living Well with
Fibromyalgia (FM) contained 13 modules segregated into three broad segments: (a) educational lec-
tures providing background knowledge about FM as a disease state, (b) education, behavioral, and
cognitive skills designed to help with symptom management, and (c) behavioral and cognitive skills
designed to facilitate adaptive life style changes for managing FM. Each of the 13 modules featured a
video lecture on the topic by a clinician experienced in applying the selected topic with respect to FM,
written summaries of the video lecture for reading or downloading, homework and self-monitoring
forms for applying the behavioral strategies described in the video lecture, and supplemental educa-
tional materials unique to each topic (e.g., audio relaxation exercises and readings)"

\section{Outcomes}

Primary pain outcome: BPI

Primary disability outcome: The Short Form-36 Physical Functioning Scale

Primary depression outcome: CES-D

Primary anxiety outcome: Stait-Trait Personality Inventory

1. Multidimensional Fatigue Inventory

2. PGIC

3. Mini-International Neuropsychiatric Interview

4.Client Satisfaction Questionnaire

Notes

Risk of bias

\begin{tabular}{lll}
\hline Bias & Authors' judgement & Support for judgement \\
\hline $\begin{array}{l}\text { Random sequence genera- } \\
\text { tion (selection bias) }\end{array}$ & Low risk & $\begin{array}{l}\text { Participants were randomly assigned to a treatment condition in a 1:1 ratio. A } \\
\text { computerised randomisation program assisted in the development of the allo- } \\
\text { cation sequence for the study }\end{array}$ \\
\hline
\end{tabular}

\begin{tabular}{|c|c|c|}
\hline $\begin{array}{l}\text { Allocation concealment } \\
\text { (selection bias) }\end{array}$ & Low risk & $\begin{array}{l}\text { Allocation concealment was utilised to prevent selection bias and group as- } \\
\text { signment was given to both the participant and selected study staff only after } \\
\text { completion of the baseline assessments }\end{array}$ \\
\hline
\end{tabular}

Blinding (performance Low risk Assessments taken online

bias and detection bias)

All outcomes

$\begin{array}{lll}\begin{array}{l}\text { Incomplete outcome data } \\ \text { (attrition bias) }\end{array} & \text { Unclear risk } & \begin{array}{l}\text { Attrition reported. Differences between completers and non-completers not } \\ \text { reported }\end{array} \\ \text { All outcomes } & \end{array}$

\begin{tabular}{lll}
\hline $\begin{array}{l}\text { Selective reporting (re- } \\
\text { porting bias) }\end{array}$ & Low risk & Published report includes data for all expected outcomes \\
\hline Other bias & Low risk & Study appears to be free of other sources of bias \\
\hline
\end{tabular}


ACT = Acceptance Commitment Therapy

$\mathrm{BDI}=$ Beck Depression Inventory

$\mathrm{BPI}=$ Brief Pain Inventory-Short Form

$\mathrm{CBT}=$ Cognitive Behavioural Therapy

CES-D = Centre for Epidemiological Studies Short Depression Scale

$\mathrm{CPCl}=$ Chronic Pain Coping Inventory

DASS $=$ Depression Anxiety Stress Scale

$\mathrm{F}=$ Female

$\mathrm{FABQ}=$ Fear Avoidance Beliefs Questionnaire

HADS = Hospital Anxiety and Depression Scale

$\mathrm{HDI}=$ Headache Disability Inventory

$M=$ Male

$\mathrm{MPI}=$ Multidimensional Pain Inventory

PAIRS = Pain and Impairment Relationship Scale

PCS = Pain Catastrophizing Scale

PGIC = Patient Global Impression of Change

$\mathrm{RCT}=$ Randomized controlled trial

$\mathrm{SD}=$ Standard deviation

STAI = State-Trait Anxiety Inventory

Characteristics of excluded studies [ordered by study ID]

\begin{tabular}{|c|c|}
\hline Study & Reason for exclusion \\
\hline Allen 2008 & Does not use the Internet as primary mode of delivering treatment \\
\hline Anderson 2006 & Not chronic non-cancer pain \\
\hline Andersson 2002 & Inadequate $n$ : number of participants in any study arm was less than 20 \\
\hline Bieber 2006 & Does not evaluate a self-management psychological intervention \\
\hline Borckardt 2004 & Not a randomised control trial \\
\hline Brattberg 2006 & Inadequate n: number of participants in any study arm was less than 20 \\
\hline Brattberg 2007 & Inadequate n: number of participants in any study arm was less than 20 \\
\hline Bruce 2005 & Does not evaluate a self-management psychological intervention \\
\hline Chambers 2006 & Not chronic non-cancer pain \\
\hline Childs 2011 & Does not use the Internet as primary mode of delivering treatment \\
\hline Cleeland 2011 & Not chronic non-cancer pain \\
\hline de Bruijn-Kofman 1997 & Not a randomised control trial \\
\hline Everitt 2010 & Not chronic non-cancer pain \\
\hline Everitt 2013 & Not chronic non-cancer pain \\
\hline Fraenkel 2007 & Does not evaluate a self-management psychological intervention \\
\hline Greco 2004 & Does not use the Internet as primary mode of delivering treatment \\
\hline Hochlehnert 2006 & Does not evaluate a self-management psychological intervention \\
\hline
\end{tabular}




\begin{tabular}{|c|c|}
\hline Study & Reason for exclusion \\
\hline Huffstutter 2007 & Does not evaluate a self-management psychological intervention \\
\hline Jacobs 2013 & Not a randomised control trial \\
\hline Jennings 2008 & Does not use the Internet as primary mode of delivering treatment \\
\hline Johns 2011 & Not chronic non-cancer pain \\
\hline Keulers 2007 & Does not evaluate a self-management psychological intervention \\
\hline Kjeken 2011 & Does not use the Internet as primary mode of delivering treatment \\
\hline Kleiboer 2009 & Used a non-inferiority hypothesis \\
\hline Kosterink 2010 & Does not use the Internet as primary mode of delivering treatment \\
\hline Krein 2010 & Intervention has insufficient psychotherapeutic content \\
\hline Kristjansdottir 2011 & Does not use the Internet as primary mode of delivering treatment \\
\hline Kristjansdottir 2013 & Does not use the Internet as primary mode of delivering treatment \\
\hline Kroenke 2010 & Not chronic non-cancer pain \\
\hline Larsman 2010 & Does not use the Internet as primary mode of delivering treatment \\
\hline Leboeuf-Yde 2012 & Not a randomised control trial \\
\hline Leveille 2007 & Not a randomised control trial \\
\hline Leville 2009 & Intervention has insufficient psychotherapeutic content \\
\hline Lorig 2002 & Intervention has insufficient psychotherapeutic content \\
\hline Lorig 2006 & Not chronic non-cancer pain \\
\hline Macedo 2012 & Does not evaluate a self-management psychological intervention \\
\hline Miller 2010 & Not chronic non-cancer pain \\
\hline Naylor 2008 & Does not use the Internet as primary mode of delivering treatment \\
\hline Naylor 2010 & Does not use the Internet as primary mode of delivering treatment \\
\hline Oerlemans 2011 & Not chronic non-cancer pain \\
\hline Premi 1993 & Not chronic non-cancer pain \\
\hline Russell 2011 & Used a non-inferiority hypothesis \\
\hline Sandsjo 2010 & Does not evaluate a self-management psychological intervention \\
\hline Sciamanna 2006 & Does not evaluate a self-management psychological intervention \\
\hline Spunt 1996 & Not a randomised control trial \\
\hline
\end{tabular}




\begin{tabular}{ll}
\hline Study & Reason for exclusion \\
\hline Steel 2011 & Not chronic non-cancer pain \\
\hline Taieb-Maimon 2012 & Not chronic non-cancer pain \\
\hline Vonk Noordegraaf 2012 & Does not use the Internet as primary mode of delivering treatment \\
\hline Weingart 2008 & Not chronic non-cancer pain \\
\hline
\end{tabular}

\section{DATA AND ANALYSES}

\section{Comparison 1. Headache post treatment}

\begin{tabular}{lllll}
\hline $\begin{array}{l}\text { Outcome or sub- } \\
\text { group title }\end{array}$ & $\begin{array}{l}\text { No. of } \\
\text { studies }\end{array}$ & $\begin{array}{l}\text { No. of } \\
\text { partici- } \\
\text { pants }\end{array}$ & Statistical method & Effect size \\
\hline 1 Pain & 2 & 131 & Risk Ratio (M-H, Random, 95\% Cl) & $7.28[2.67,19.84]$ \\
\hline 2 Disability & 2 & 241 & Std. Mean Difference (IV, Random, 95\% Cl) & $-0.65[-0.91,-0.39]$ \\
\hline 3 Depression & 4 & 617 & Std. Mean Difference (IV, Random, 95\% Cl) & $-0.26[-0.87,0.36]$ \\
\hline 4 Anxiety & 3 & 546 & Std. Mean Difference (IV, Random, 95\% Cl) & $-0.48[-1.22,0.27]$ \\
\hline
\end{tabular}

Analysis 1.1. Comparison 1 Headache post treatment, Outcome 1 Pain.

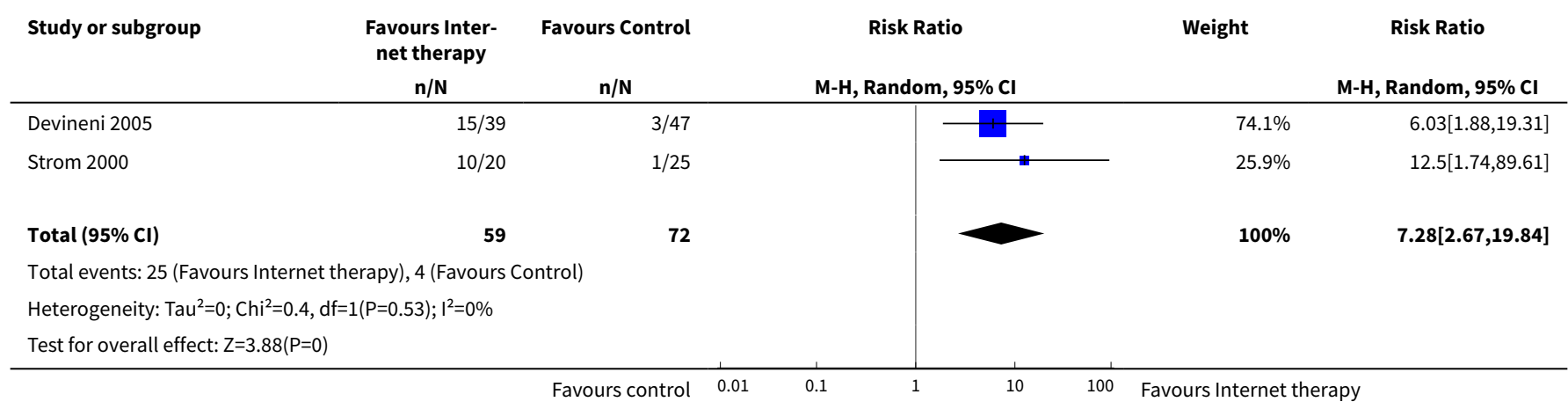

Analysis 1.2. Comparison 1 Headache post treatment, Outcome 2 Disability.

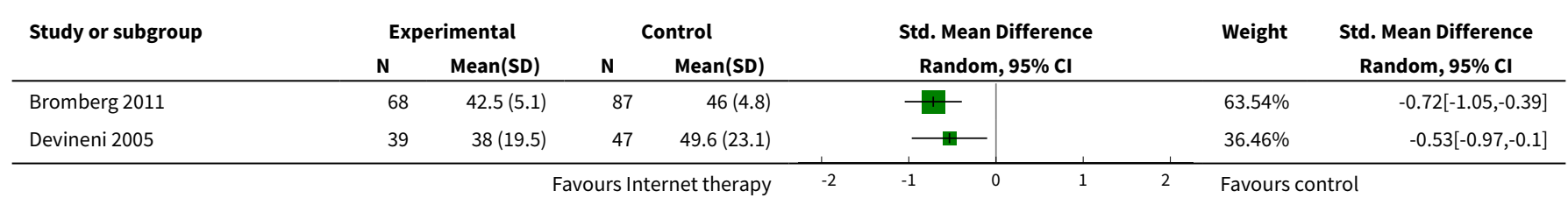




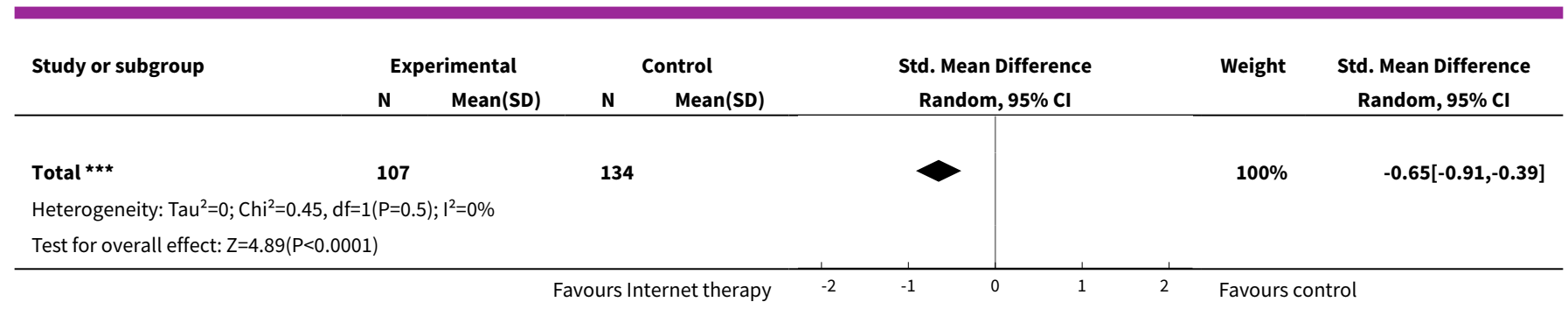

Analysis 1.3. Comparison 1 Headache post treatment, Outcome 3 Depression.

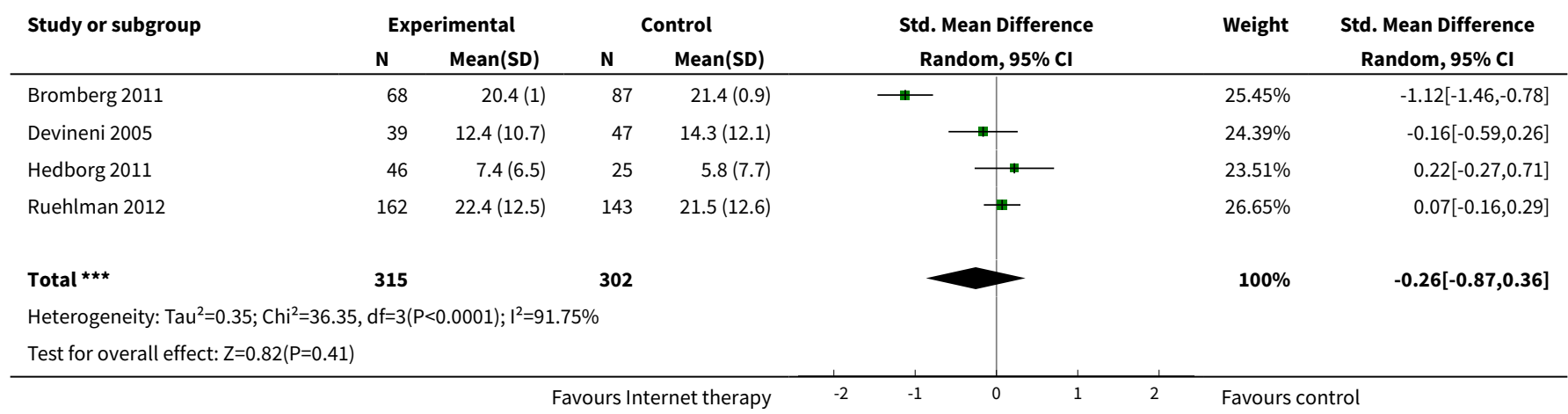

Analysis 1.4. Comparison 1 Headache post treatment, Outcome 4 Anxiety.

\begin{tabular}{|c|c|c|c|c|c|c|c|}
\hline \multirow{3}{*}{$\begin{array}{l}\text { Study or subgroup } \\
\text { Bromberg } 2011\end{array}$} & \multicolumn{2}{|c|}{ Experimental } & \multicolumn{2}{|c|}{ Control } & \multirow{2}{*}{$\begin{array}{c}\text { Std. Mean Difference } \\
\text { Random, } 95 \% \mathrm{Cl}\end{array}$} & \multirow[t]{2}{*}{ Weight } & \multirow{2}{*}{$\begin{array}{c}\text { Std. Mean Difference } \\
\text { Random, } 95 \% \mathrm{Cl}\end{array}$} \\
\hline & $\mathbf{N}$ & Mean(SD) & $\mathbf{N}$ & Mean(SD) & & & \\
\hline & 68 & $18.9(0.8)$ & 87 & $19.9(0.8)$ & $\mp-$ & $33.24 \%$ & $-1.23[-1.57,-0.88]$ \\
\hline Devineni 2005 & 39 & $18.4(15.7)$ & 47 & $20.8(17.2)$ & 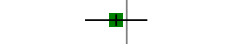 & $32.08 \%$ & $-0.14[-0.57,0.28]$ \\
\hline Ruehlman 2012 & 162 & $4.5(4.6)$ & 143 & $4.8(4.7)$ & \# & $34.68 \%$ & $-0.07[-0.29,0.16]$ \\
\hline 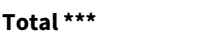 & 269 & & 277 & & & $100 \%$ & $-0.48[-1.22,0.27]$ \\
\hline \multicolumn{8}{|c|}{ Heterogeneity: $\mathrm{Tau}^{2}=0.4 ; \mathrm{Chi}^{2}=31.61, \mathrm{df}=2(\mathrm{P}<0.0001) ; \mathrm{I}^{2}=93.67 \%$} \\
\hline Test for overall effect & & & & & & & \\
\hline
\end{tabular}

\section{Comparison 2. Headache follow-up}

\begin{tabular}{lllll}
\hline $\begin{array}{l}\text { Outcome or subgroup } \\
\text { title }\end{array}$ & $\begin{array}{l}\text { No. of } \\
\text { studies }\end{array}$ & $\begin{array}{l}\text { No. of par- } \\
\text { ticipants }\end{array}$ & Statistical method & Effect size \\
\hline 1 Depression & 2 & 425 & Std. Mean Difference (IV, Random, 95\% CI) & $-1.03[-3.18,1.12]$ \\
\hline 2 Anxiety & 2 & 425 & Std. Mean Difference (IV, Random, 95\% Cl) & $-0.46[-1.09,0.18]$ \\
\hline
\end{tabular}


Analysis 2.1. Comparison 2 Headache follow-up, Outcome 1 Depression.

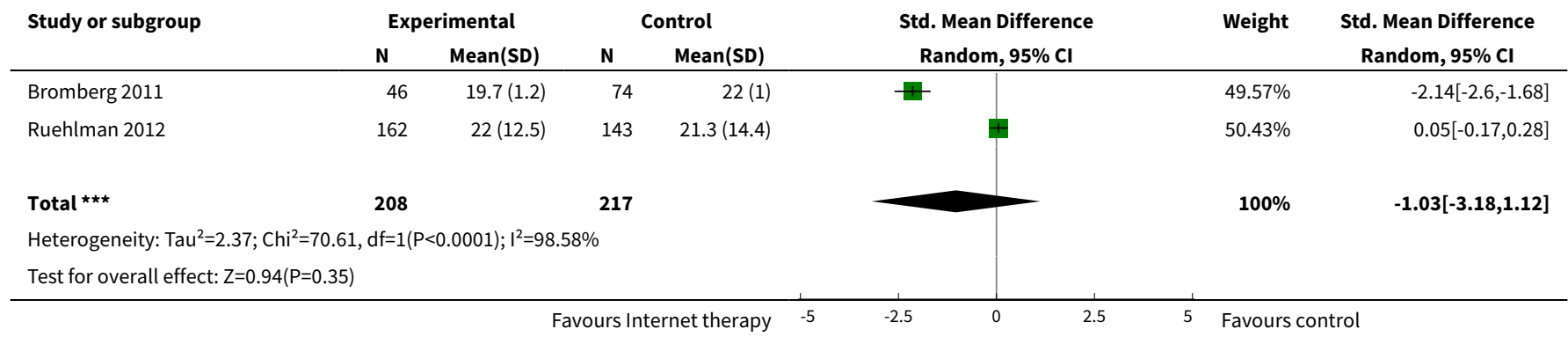

Analysis 2.2. Comparison 2 Headache follow-up, Outcome 2 Anxiety.

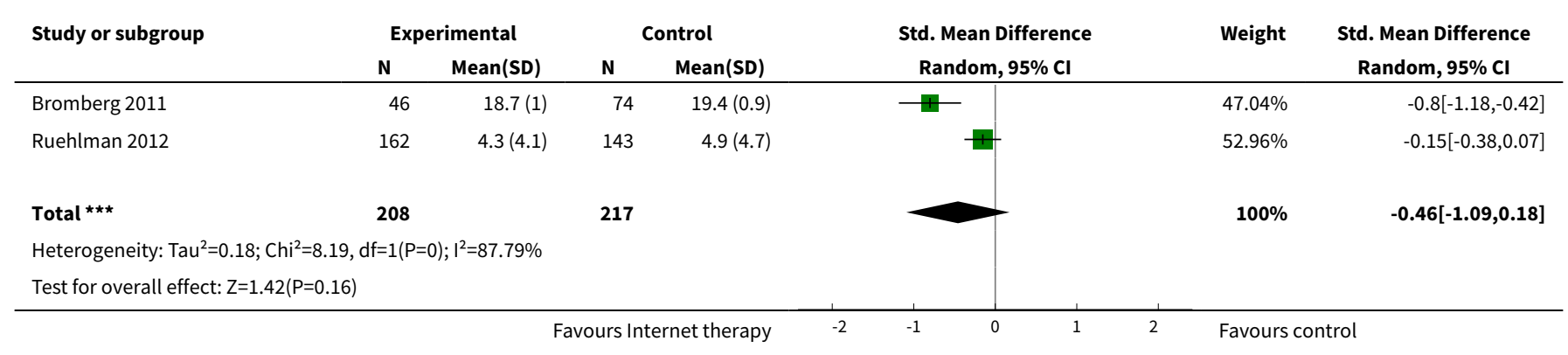

\section{Comparison 3. Non-headache post treatment}

\begin{tabular}{lllll}
\hline $\begin{array}{l}\text { Outcome or sub- } \\
\text { group title }\end{array}$ & $\begin{array}{l}\text { No. of } \\
\text { studies }\end{array}$ & $\begin{array}{l}\text { No. of } \\
\text { partici- } \\
\text { pants }\end{array}$ & Statistical method & Effect size \\
\hline 1 Pain & 11 & 1785 & Std. Mean Difference (IV, Random, 95\% Cl) & $-0.37[-0.59,-0.15]$ \\
\hline 2 Disability & 5 & 1149 & Std. Mean Difference (IV, Random, 95\% Cl) & $-0.50[-0.79,-0.20]$ \\
\hline 3 Depression & 9 & 1013 & Std. Mean Difference (IV, Random, 95\% Cl) & $-0.19[-0.35,-0.04]$ \\
\hline 4 Anxiety & 10 & 1144 & Std. Mean Difference (IV, Random, 95\% Cl) & $-0.28[-0.49,-0.06]$ \\
\hline 5 Quality of life & 3 & 202 & Std. Mean Difference (IV, Random, 95\% CI) & $-0.27[-0.54,0.01]$ \\
\hline
\end{tabular}

Analysis 3.1. Comparison 3 Non-headache post treatment, Outcome 1 Pain.

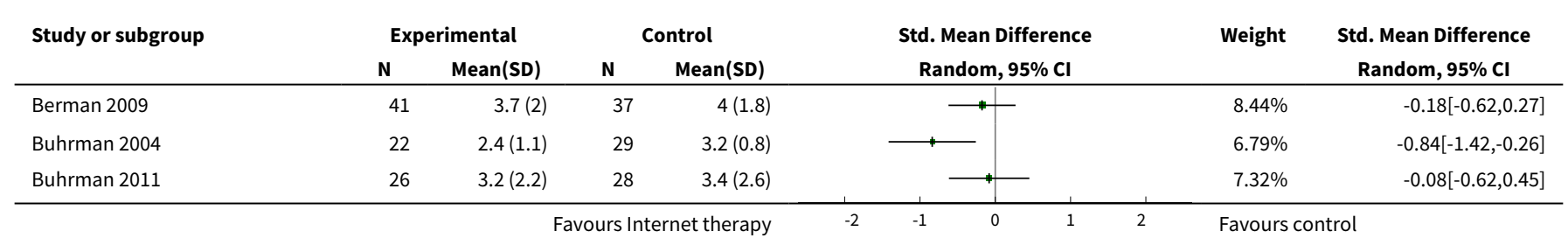




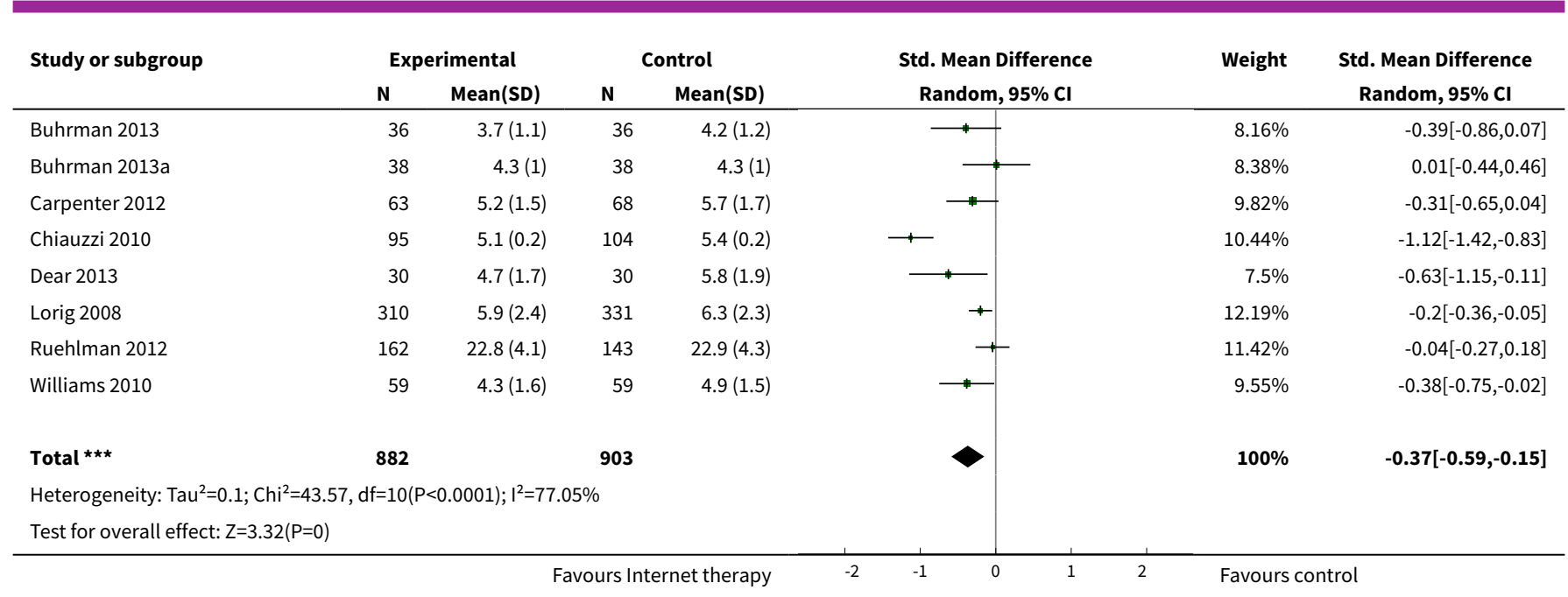

Analysis 3.2. Comparison 3 Non-headache post treatment, Outcome 2 Disability.

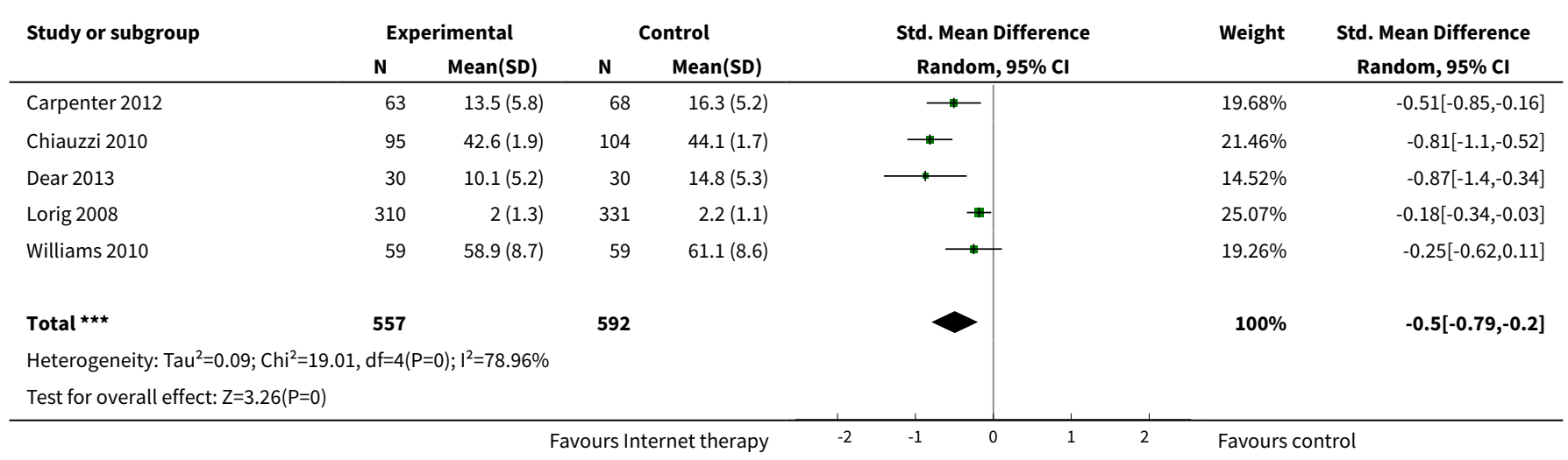

Analysis 3.3. Comparison 3 Non-headache post treatment, Outcome 3 Depression.

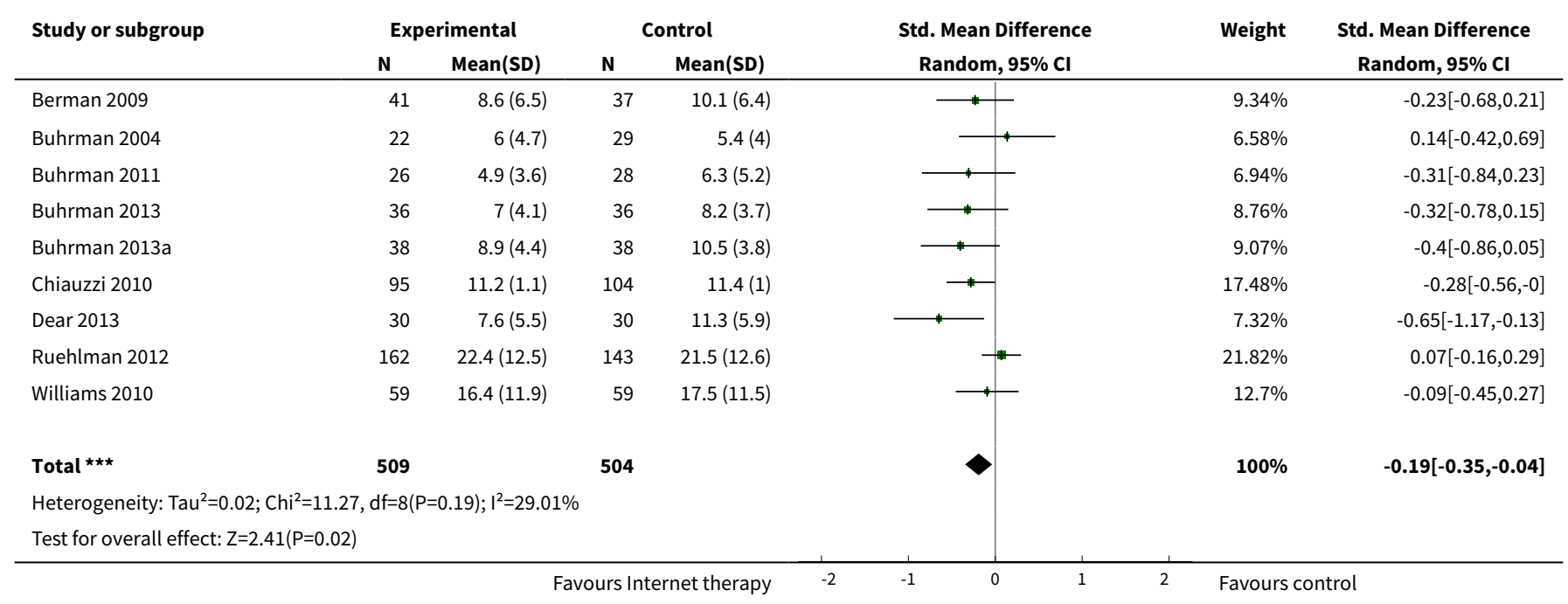


Analysis 3.4. Comparison 3 Non-headache post treatment, Outcome 4 Anxiety.

\begin{tabular}{|c|c|c|c|c|c|c|c|}
\hline \multirow{3}{*}{$\begin{array}{l}\text { Study or subgroup } \\
\text { Berman } 2009\end{array}$} & \multicolumn{2}{|c|}{ Experimental } & \multicolumn{2}{|c|}{ Control } & \multirow{2}{*}{$\begin{array}{c}\text { Std. Mean Difference } \\
\text { Random, } 95 \% \mathrm{Cl}\end{array}$} & \multirow[t]{2}{*}{ Weight } & \multirow{2}{*}{$\begin{array}{c}\text { Std. Mean Difference } \\
\text { Random, } 95 \% \mathrm{Cl}\end{array}$} \\
\hline & $\mathbf{N}$ & Mean(SD) & $\mathbf{N}$ & $\operatorname{Mean}(S D)$ & & & \\
\hline & 41 & $10.9(4.8)$ & 37 & $11.3(3.9)$ & $\longrightarrow$ & $9.45 \%$ & $-0.1[-0.54,0.35]$ \\
\hline Buhrman 2004 & 22 & $7.2(4)$ & 29 & $6(3.3)$ & $\longrightarrow$ & $7.64 \%$ & $0.33[-0.23,0.88]$ \\
\hline Buhrman 2011 & 26 & $5.8(3.5)$ & 28 & $7(6)$ & 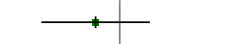 & $7.97 \%$ & $-0.24[-0.77,0.3]$ \\
\hline Buhrman 2013 & 36 & $7.2(3.9)$ & 36 & $9.1(4.4)$ & 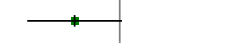 & $9.05 \%$ & $-0.45[-0.91,0.02]$ \\
\hline Buhrman 2013a & 38 & $9(4.3)$ & 38 & $9.7(3.5)$ & 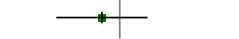 & $9.35 \%$ & $-0.18[-0.63,0.27]$ \\
\hline Chiauzzi 2010 & 95 & $7.7(1)$ & 104 & $8.4(0.9)$ & $\longrightarrow$ & $12.42 \%$ & $-0.75[-1.03,-0.46]$ \\
\hline Dear 2013 & 30 & $7.2(4.8)$ & 30 & $9(4.8)$ & $\longrightarrow$ & $8.36 \%$ & $-0.37[-0.88,0.14]$ \\
\hline Ruehlman 2012 & 162 & $4.5(4.6)$ & 143 & $4.8(4.7)$ & $\rightarrow$ & $13.62 \%$ & $-0.07[-0.29,0.16]$ \\
\hline Williams 2010 & 59 & $18.1(7.1)$ & 59 & $18.4(5.9)$ & 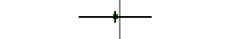 & $11 \%$ & $-0.05[-0.41,0.32]$ \\
\hline 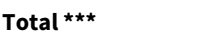 & 572 & & 572 & & & $100 \%$ & $-0.28[-0.49,-0.06]$ \\
\hline \multicolumn{8}{|c|}{ Heterogeneity: $\operatorname{Tau}^{2}=0.07 ; \mathrm{Chi}^{2}=26.55, \mathrm{df}=9(\mathrm{P}=0) ; \mathrm{I}^{2}=66.11 \%$} \\
\hline \multicolumn{3}{|c|}{ Test for overall effect: $\mathrm{Z}=2.54(\mathrm{P}=0.01)$} & & & & & \\
\hline
\end{tabular}

Analysis 3.5. Comparison 3 Non-headache post treatment, Outcome 5 Quality of life.

\begin{tabular}{|c|c|c|c|c|c|c|c|}
\hline \multirow[t]{2}{*}{ Study or subgroup } & \multicolumn{2}{|c|}{ Experimental } & \multicolumn{2}{|c|}{ Control } & \multirow{2}{*}{$\begin{array}{c}\text { Std. Mean Difference } \\
\text { Random, } 95 \% \mathrm{Cl} \\
\end{array}$} & \multirow[t]{2}{*}{ Weight } & \multirow{2}{*}{$\begin{array}{c}\text { Std. Mean Difference } \\
\text { Random, } 95 \% \mathrm{Cl}\end{array}$} \\
\hline & $\mathbf{N}$ & Mean(SD) & $\mathbf{N}$ & Mean(SD) & & & \\
\hline Buhrman 2011 & 26 & $-1.7(1.4)$ & 28 & $-1.1(1.6)$ & $\longrightarrow$ & $26.48 \%$ & $-0.39[-0.93,0.15]$ \\
\hline Buhrman 2013 & 36 & $-1.3(2.1)$ & 36 & $-0.6(1.7)$ & 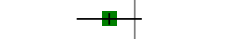 & $35.46 \%$ & $-0.36[-0.83,0.1]$ \\
\hline Buhrman 2013a & 38 & $-0.6(2.1)$ & 38 & $-0.4(1.8)$ & 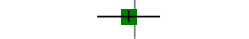 & $38.05 \%$ & $-0.09[-0.54,0.36]$ \\
\hline 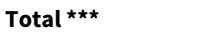 & 100 & & 102 & & & $100 \%$ & $-0.27[-0.54,0.01]$ \\
\hline \multicolumn{3}{|c|}{ Test for overall effect: $Z=1.88(P=0.06)$} & & & & & \\
\hline & & & 15 & et therapy & -1 & Favours & rol \\
\hline
\end{tabular}

\section{Comparison 4. Non-headache follow-up}

\begin{tabular}{lllll}
\hline $\begin{array}{l}\text { Outcome or sub- } \\
\text { group title }\end{array}$ & $\begin{array}{l}\text { No. of } \\
\text { studies }\end{array}$ & $\begin{array}{l}\text { No. of } \\
\text { partici- } \\
\text { pants }\end{array}$ & Statistical method & Effect size \\
\hline 1 Pain & 4 & 1202 & Std. Mean Difference (IV, Random, 95\% CI) & $-0.48[-1.18,0.22]$ \\
\hline 2 Disability & 2 & 850 & Std. Mean Difference (IV, Fixed, 95\% Cl) & $-0.15[-0.28,-0.01]$ \\
\hline 3 Depression & 3 & 551 & Std. Mean Difference (IV, Random, 95\% CI) & $-0.53[-1.84,0.78]$ \\
\hline 4 Anxiety & 3 & 551 & Std. Mean Difference (IV, Random, 95\% CI) & $-0.39[-1.25,0.47]$ \\
\hline
\end{tabular}


Analysis 4.1. Comparison 4 Non-headache follow-up, Outcome 1 Pain.

\begin{tabular}{|c|c|c|c|c|c|c|c|}
\hline \multirow[t]{2}{*}{ Study or subgroup } & \multicolumn{2}{|c|}{ Experimental } & \multicolumn{2}{|c|}{ Control } & \multirow{2}{*}{$\begin{array}{c}\text { Std. Mean Difference } \\
\text { Random, } 95 \% \mathrm{Cl}\end{array}$} & \multirow[t]{2}{*}{ Weight } & \multirow{2}{*}{$\begin{array}{c}\text { Std. Mean Difference } \\
\text { Random, } 95 \% \mathrm{Cl}\end{array}$} \\
\hline & $\mathbf{N}$ & $\operatorname{Mean}(\mathrm{SD})$ & $\mathbf{N}$ & Mean(SD) & & & \\
\hline Buhrman 2004 & 21 & $3(1.3)$ & 26 & $3.1(1.2)$ & $\longrightarrow$ & $22.57 \%$ & $-0.08[-0.65,0.5]$ \\
\hline Chiauzzi 2010 & 95 & $4.8(0.3)$ & 104 & $5.2(0.2)$ & $\rightarrow$ & $25.19 \%$ & $-1.7[-2.02,-1.37]$ \\
\hline Lorig 2008 & 307 & $5.8(2.5)$ & 344 & $6.1(2.4)$ & $*$ & $26.31 \%$ & $-0.14[-0.29,0.02]$ \\
\hline Ruehlman 2012 & 162 & $22.4(4.3)$ & 143 & $22.3(4.6)$ & $\leftarrow$ & $25.93 \%$ & $0.02[-0.21,0.24]$ \\
\hline \multicolumn{8}{|c|}{ Heterogeneity: Tau $^{2}=0.48 ; \mathrm{Chi}^{2}=83.42, \mathrm{df}=3(\mathrm{P}<0.0001) ; \mathrm{I}^{2}=96.4 \%$} \\
\hline \multicolumn{8}{|c|}{ Test for overall effect: $\mathrm{Z}=1.34(\mathrm{P}=0.18)$} \\
\hline
\end{tabular}

Analysis 4.2. Comparison 4 Non-headache follow-up, Outcome 2 Disability.

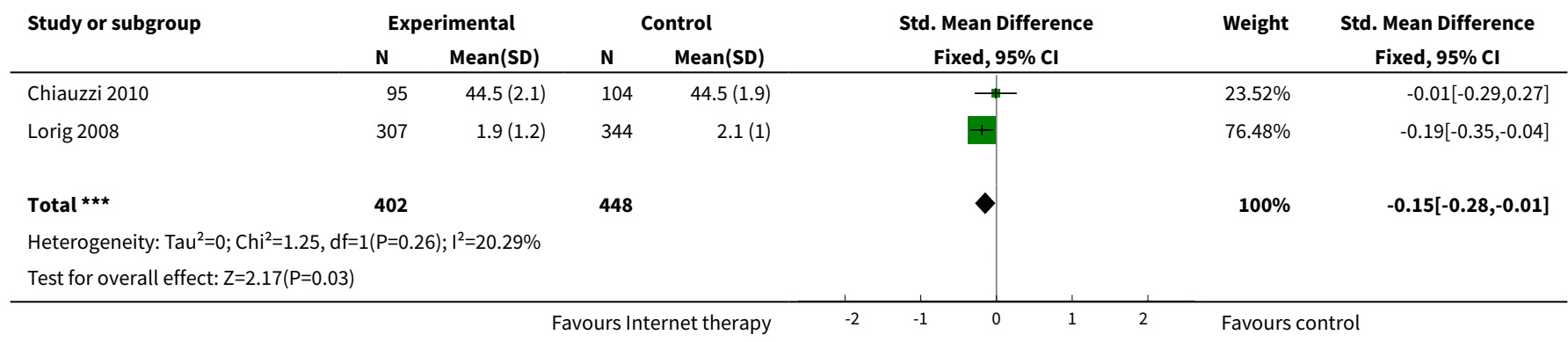

Analysis 4.3. Comparison 4 Non-headache follow-up, Outcome 3 Depression.

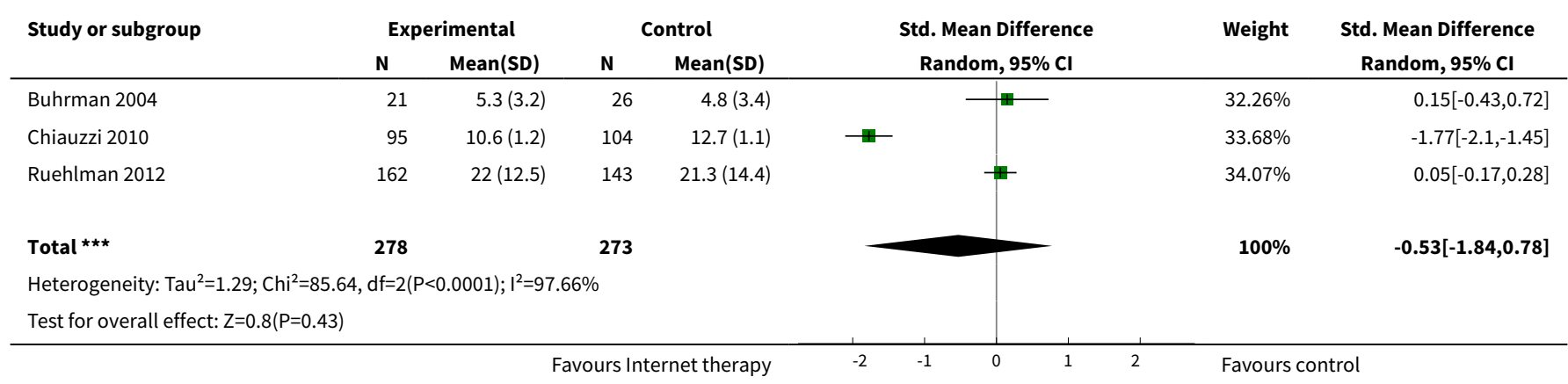

Analysis 4.4. Comparison 4 Non-headache follow-up, Outcome 4 Anxiety.

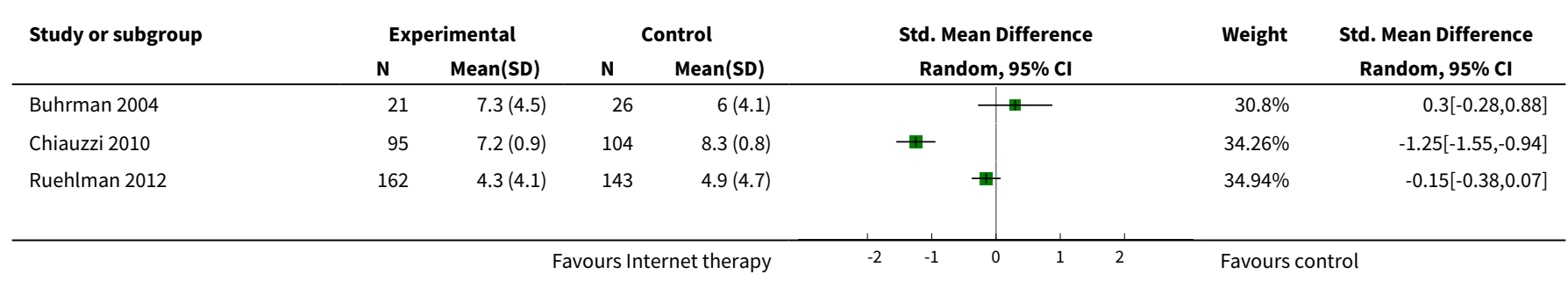




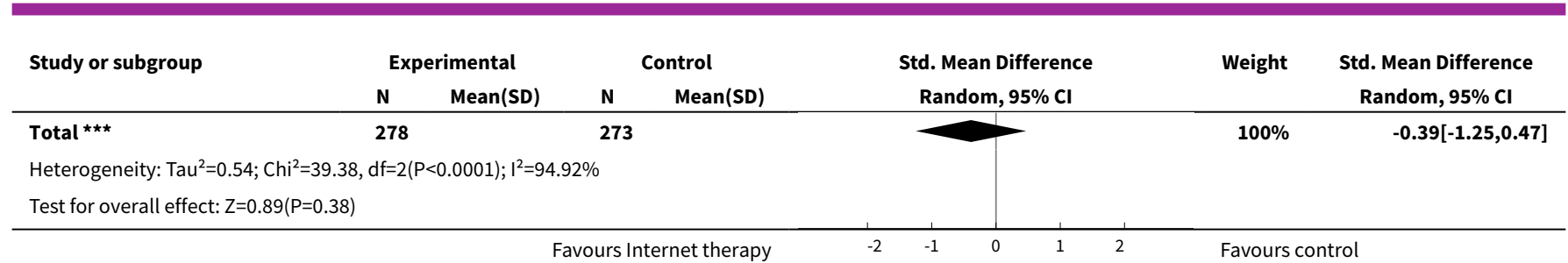

Favours Internet therapy

Favours control

\section{AP PE N DICES}

\section{Appendix 1. Search strategies}

\section{CENTRAL search strategy}

\#1 MeSH descriptor: [Telecommunications] explode all trees

\#2 (telemedicine or tele-medicine)

\#3 (telehealth or tele-health)

\#4 (ehealth or e-health)

\#5 (mobile health or mhealth or m-health)

\#6 $\quad$ ICT

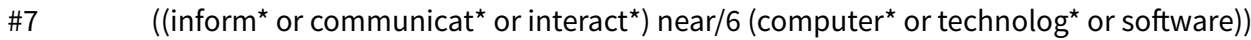

\#8 (health* ${ }^{\star}$ or treat* ${ }^{\star}$ or therap* ${ }^{\star}$ or intervention* or assist $^{\star}$ or selfmanag* or self-manag $\left.{ }^{\star}\right)$ near/6 (computer ${ }^{\star}$ or technolog* or software)

\#99 MeSH descriptor: [Internet] explode all trees

\#10 (internet* or world wide web or www or web-based or email or e-mail or online)

\#11 (telephone* or phone* or mobile* or cellphone* or apps or text* or SMS or smartphone*)

\#12 (virtual reality or augmented reality or VR or AR)

$\# 13 \quad \# 1$ or \#2 or \#3 or \#4 or \#5 or \#6 or \#7 or \#8 or \#9 or \#10 or \#11 or \#12

\#14 MeSH descriptor: [Pain] explode all trees

\#15 MeSH descriptor: [Pain Measurement] this term only

\#16 MeSH descriptor: [Headache Disorders] explode all trees

\#17 MeSH descriptor: [Fibromyalgia] this term only

\#18 (pain* or headache* or migraine* or fibromyalgia* or neuralgia*)

\#19 \#14 or \#15 or \#16 or \#17 or \#18

\#20

$\# 13$ and \#19

\section{MEDLINE search strategy}

1 exp Telecommunications/

2 (telemedicine or tele-medicine).mp.

3 (telehealth or tele-health).mp.

4 (ehealth or e-health).mp.

5 (mobile health or mhealth or m-health).mp.

6 ICT.mp.

7 ((inform ${ }^{\star}$ or communicat ${ }^{\star}$ or interact $\left.{ }^{\star}\right)$ adj6 (computer ${ }^{\star}$ or technolog* or software)).mp.

Psychological therapies (Internet-delivered) for the management of chronic pain in adults (Review) 
8 ((health* or treat $^{\star}$ or therap ${ }^{\star}$ or intervention ${ }^{\star}$ or assist $^{\star}$ or selfmanag* or self-manag ${ }^{\star}$ ) adj6 (computer ${ }^{\star}$ or technolog* or software)).mp. 9 exp Internet/

10 (internet* ${ }^{\star}$ or world wide web or www or web-based or email or e-mail or online).mp.

11 (telephone $^{\star}$ or phone ${ }^{\star}$ or mobile* or cellphone* or apps or text ${ }^{\star}$ or SMS or smartphone ${ }^{\star}$ ).mp.

12 (virtual reality or augmented reality or VR or AR).mp.

131 or 2 or 3 or 4 or 5 or 6 or 7 or 8 or 9 or 10 or 11 or 12

14 exp Pain/

15 Pain Measurement/

16 exp Headache Disorders/

17 Fibromyalgia/

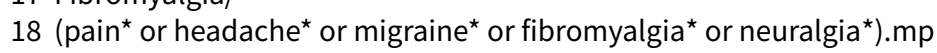

1914 or 15 or 16 or 17 or 18

20 randomized controlled trial.pt.

21 controlled clinical trial.pt.

22 randomized.ab.

23 placebo.ab.

24 clinical trials as topic.sh.

25 randomly.ab.

26 trial.ti.

2720 or 21 or 22 or 23 or 24 or 25 or 26

2813 and 19 and 27

\section{Key:}

$\mathrm{mp}=$ protocol supplementary concept, rare disease supplementary concept, title, original title, abstract, name of substance word, subject heading word, unique identifier

$a b=a b s t r a c t$

ti=title

$\mathrm{pt}=$ publication type

sh=subject heading

\section{EMBASE (OVID) search strategy}

1 exp Telecommunications/

2 (telemedicine or tele-medicine).tw.

3 (telehealth or tele-health).tw.

4 (ehealth or e-health).tw.

5 (mobile health or mhealth or m-health).tw.

6 ICT.tw.

7 ((inform ${ }^{\star}$ or communicat ${ }^{\star}$ or interact $\left.{ }^{\star}\right)$ adj6 (computer ${ }^{\star}$ or technolog* or software)).tw.

8 ((health* or treat $^{\star}$ or therap ${ }^{\star}$ or intervention ${ }^{\star}$ or assist* or selfmanag $^{\star}$ or self-manag ${ }^{\star}$ ) adj6 (computer or technolog $^{\star}$ or software)).tw.

9 exp Internet/

10 (internet* or world wide web or www or web-based or email or e-mail or online).tw.

11 (telephone* or phone* or mobile* or cellphone* or apps or text* or SMS or smartphone*).tw.

12 (virtual reality or augmented reality or VR or AR).tw.

13 or $/ 1-12$

14 exp Pain/

15 Pain Measurement/

Psychological therapies (Internet-delivered) for the management of chronic pain in adults (Review) 
16 exp Headache Disorders/

17 Fibromyalgia/

18 (pain $^{\star}$ or headache ${ }^{\star}$ or migraine ${ }^{\star}$ or fibromyalgia* or neuralgia*).tw.

19 or/14-18

20 random\$.tw.

21 factorial\$.tw.

22 crossover\$.tw.

23 cross over\$.tw.

24 cross-over\$.tw.

25 placebo\$.tw.

26 (doubl\$ adj blind\$).tw.

27 (singl\$ adj blind\$).tw.

28 assign\$.tw.

29 allocat\$.tw.

30 volunteer\$.tw.

31 crossover procedure/

32 double blind procedure/

33 randomized controlled trial/

34 single blind procedure/

35 or $/ 20-34$

36 (animal/ or nonhuman/) not human/

$37 \quad 35$ not 36

$38 \quad 13$ and 19 and 37

\section{PsycINFO (OVID) search strategy}

1 exp Telecommunications/

2 (telemedicine or tele-medicine).tw.

3 (telehealth or tele-health).tw.

4 (ehealth or e-health).tw.

5 (mobile health or mhealth or m-health).tw.

6 ICT.tw.

7 ((inform or communicat $^{\star}$ or interact $\left.{ }^{\star}\right)$ adj6 (computer ${ }^{\star}$ or technolog ${ }^{\star}$ or software)).tw.

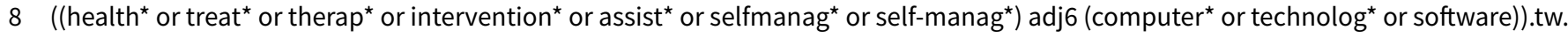

9 exp Internet/

10 (internet* or world wide web or www or web-based or email or e-mail or online).tw.

Psychological therapies (Internet-delivered) for the management of chronic pain in adults (Review) 
11 (telephone* or phone $^{\star}$ or mobile* or cellphone* or apps or text ${ }^{\star}$ or SMS or smartphone ${ }^{\star}$ ).tw.

12 (virtual reality or augmented reality or VR or AR).tw.

13 or $/ 1-12$

14 exp Pain/

15 Pain Measurement/

16 exp Headache/

17 Fibromyalgia/

18 (pain $^{\star}$ or headache* or migraine* or fibromyalgia* or neuralgia*).tw.

19 or/14-18

$20 \quad 13$ and 19

21 clinical trials/

22 (randomis* or randomiz*).tw.

23 (random\$ adj3 (allocat\$ or assign\$)).tw.

24 ((clinic\$ or control\$) adj trial\$).tw.

25 ((singl\$ or doubl\$ or trebl\$ or tripl\$) adj3 (blind\$ or mask\$)).tw.

26 (crossover\$ or "cross over\$").tw.

27 random sampling/

28 Experiment Controls/

29 Placebo/

30 placebo\$.tw.

31 exp program evaluation/

32 treatment effectiveness evaluation/

33 ((effectiveness or evaluat\$) adj3 (stud\$ or research\$)).tw.

34 or/21-33

$35 \quad 20$ and 34

WHAT'S NEW

\begin{tabular}{lll}
\hline Date & Event & Description \\
\hline 30 September 2019 & Amended & Clarification added to Declarations of interest. \\
\hline 7 August 2019 & Review declared as stable & See Published notes. \\
\hline
\end{tabular}

\section{H I S T OR Y}

Protocol first published: Issue 10, 2012

Review first published: Issue 2, 2014

Psychological therapies (Internet-delivered) for the management of chronic pain in adults (Review) 


\begin{tabular}{lll}
\hline Date & Event & Description \\
\hline 9 February 2016 & Review declared as stable & See Published notes.
\end{tabular}

\section{CONTRIBUTIONS OF AUTHORS}

CE conceived the idea, and led the design and delivery of the review, and contributed to the writing. CE, EF, LC, GBD, BAR and EK contributed to the design and writing of the protocol. CE, GBD, EF and LC selected studies for inclusion. EF and LC extracted data and assessed risk of bias. CE, EF and LC analysed data. EK contributed to writing and oversaw the review process.

\section{DECLARATIONS OF INTEREST}

None known.

Since $C E$ is an author as well as the PaPaS Co-ordinating Editor at the time of writing, we acknowledge the input of Amanda $\mathrm{C}$ de $\mathrm{C}$ Williams who acted as Sign Off Editor for this review. CE had no input into the editorial decisions or processes for this review.

\section{SOURCES OF SUPPORT}

\section{Internal sources}

- No sources of support supplied

\section{External sources}

- EPSRC, UK.

\section{DIFFERENCES BETWEEN PROTOCOLANDREVIEW}

There are no differences between the protocol and the review.

\section{N O T E S}

\section{6}

At February 2016, there are no new potentially relevant studies likely to change the conclusions. Therefore, this review has now been stabilised following discussion with the authors and editors. The review will be re-assessed for updating in 2017.

\section{9}

This review was reassessed for updating in 2018. The authors and editors agreed that this should be superseded by a new review, Psychological therapies (remotely delivered) for the management of chronic pain in adults, which will serve to update and replace this version. The new title was registered in 2019.

\section{N DEX TERM S}

\section{Medical Subject Headings (MeSH)}

*Internet; Anxiety [therapy]; Chronic Pain [psychology] [*therapy]; Cognitive Behavioral Therapy [*methods]; Depression [therapy]; Headache [psychology] [ ${ }^{\star}$ therapy]; Pain Management [ ${ }^{\star}$ methods]; Randomized Controlled Trials as Topic

\section{MeSH check words}

Adult; Humans 